\title{
Efficacy of praziquantel and artemisinin derivatives for the treatment and prevention of human schistosomiasis: a systematic review and meta-analysis
}

\author{
Rong Liu ${ }^{1 *}$, Hui-Fen Dong ${ }^{1}$, Yi Guo ${ }^{2}$, Qin-Ping Zhao ${ }^{1}$ and Ming-Sen Jiang ${ }^{1 *}$
}

\begin{abstract}
Background: Praziquantel has been used as first-line drug for chemotherapy of schistosomiasis since 1984. Besides praziquantel, artemether and artesunate have also been used for the control of this infectious disease since late 1990s. In this article, we conducted a systematic review and meta-analysis to evaluate the antischistosomal efficacy of different medication strategies including monotherapy or combination therapies of these drugs.

Results: A number of 52 trials from 38 articles published in peer-reviewed journals before July 2011 were selected for analysis after searching the following literature databases: the Cochrane Library, PubMed/Medline, ISI Web of Science, Chinese Biomedicine Literature Database, and China National Knowledge Infrastructure. Our meta-analyses showed that a dosage of 30-60 mg/kg praziquantel compared with placebo produced a protection rate of about 76\% (95\% Cl: 67\%-83\%) for treating human schistosomiasis, which varied from $70 \%$ to $76 \%$ with no significant differences among the subspecies S. haematobium, S. japonicum or S. mansoni. Protection rates were higher when praziquantel doses were elevated, as concluded from the nRCTs results: the protection rate of praziquantel at 40 $\mathrm{mg} / \mathrm{kg}$ was 52\% (95\% Cl: 49\%-55\%), and it increased to 91\% (95\% Cl: 88\%-92\%) when the dosages were elevated to $60 / 80 / 100 \mathrm{mg} / \mathrm{kg}$ divided two or more doses. Multiple doses of artemether or artesunate over 1- or 2-week intervals resulted in protection rates of $65 \%$ to $97 \%$ for preventing schistosomiasis, and increased doses and shorter medication intervals improved their efficacies. Praziquantel and artemisinin derivatives (artemether or artesunate) in combination resulted in a higher protection rate of $84 \%$ (95\% Cl: 64\%-91\%) than praziquantel monotherapy for treatment. praziquantel and artesunate in combination had a great protection rate of 96\% (95\% Cl: 78\%-99\%) for preventing schistosomes infection.

Conclusions: According to the results, praziquantel remains effective in schistosomiasis treatment, and multiple doses would improve its efficacy; meanwhile, praziquantel is also a good drug for preventing acute schistosomiasis morbidity. It's better to use multiple doses of artemether or artesunate with 1-or 2-week intervals for prevention against schistosome infection. Praziquantel and artemether or artesunate in combination perform better in treatment than praziquantel monotherapy, and they are especially suitable for treating the patients with repeated exposure to infected water.
\end{abstract}

Keywords: human schistosomiasis, praziquantel, artemether, artesunate, efficacy, meta-analysis

\footnotetext{
* Correspondence: liurong19840901@whu.edu.cn; msjiang@whu.edu.cn 'Department of Medical Parasitology, School of Basic Medical Science, Wuhan University, Wuhan 430071, People's Republic of China Full list of author information is available at the end of the article
} 


\section{Background}

Schistosomiasis, an infectious disease caused by parasitic trematodes (schistosomes) dwelling in the host's mesenteric portal system, is a great public health problem in tropical and subtropical regions. The disease causes health and labor loss, and finally a significant reduction in socioeconomic benefits. Approximately 207 million people (more than 97\% in Africa) are infected, and 779 million (85\% in Africa) are at risk of being infected in 76 endemic countries worldwide, leading to the loss of about 4.5 million disability-adjusted life years (DALYs) [1-4]. Thus schistosomiasis control remains a challenge in endemic regions [4-7].

There are five schistosome species parasitizing in humans: Schistosoma japonicum, S. mansoni, S. haematobium, S. mekongi, and S. intercalatum. S. japonicum is transmitted by the amphibian snail Oncomelania and causes intestinal and hepatosplenic schistosomiasis in the People's Republic of China, Philippines, and Indonesia; $S$. mansoni, transmitted by Biomphalaria snails, causes intestinal and hepatic schistosomiasis in Africa, the Arabian peninsula, and South America; S. haematobium, transmitted by Bulinus snails, causes urinary schistosomiasis in Africa and the Arabian peninsula. S. mekongi and S. intercalatum are only of local importance $[1-3,8,9]$.

In the mid-1980s, the WHO recommended schistosomiasis control strategies for humans by focusing on the large-scale population-based and repeated chemotherapy, which is still the key strategy today [10]. The chemotherapy for human schistosomiasis is to take antischistosomal drugs for prevention of morbidity in high-risk population (i.e. chemoprophylaxis by preventing the young schistosomes - schistosomula developing into adult egg-laying worms or killing them), and for treatment of patients by eliminating adult worms, whose eggs deposited in human tissue (e.g. liver and intestinal wall) and caused pathogenesis. For schistosomiasis treatment three drugs have been used, which differ in their effects on schistosome species: metrifonate (targeting $S$. haematobium), oxamniquine (targeting S. mansoni), and praziquantel (PZQ) (for all human species). Due to its broader spectrum, PZQ has finally become the first-line medicine. In recent years, however, the potential resistance problem of schistosomes to PZQ has come into concern, which may necessitate searching for alternatives [4,11-15]. Among those are artemether (AM) and artesunate (AS), artemisinin derivatives (ARTs) with anti-schistosomal potential which was first described in the People's Republic of China in the early 1980s. ARTs were approved as schistosomiasis prevention drugs by the Chinese Ministry of Health in 1996 [16]. They are active against $S$. japonicum, S. mansoni and S. haematobium, mainly targeting the immature, pre-adult stage, the schistosomulum [17-21].
Only few publications, however, can be found with comprehensive and statistical assessments of the efficacy of these drugs controlling human schistosomiasis. To get a more detailed overview on the efficacy of PZQ and ARTs for human schistosomiasis treatment and prevention, we collected a large group of studies published in peer-reviewed journals, and conducted meta-analyses in categories to assess their antischistosomal efficacy comprehensively, including single drug monotherapy and drugs in combination against S. japonicum, S. mansoni, S. haematobium and S. mekongi.

\section{Methods}

\section{Search strategy and data sources}

We conducted a computer-aided search of the literature about anti-schistosomal efficacies assessments of PZQ, $\mathrm{AM}$ and AS used alone or in combination for human schistosomiasis. Source databases were the Cochrane Library (Issue 7, 2011), PubMed/Medline (1966 to July 2011), ISI Web of Science (1975 to July 2011), Chinese Bio-Medicine Literature Database (CBM, 1979 to July 2011) and China National Knowledge Infrastructure (CNKI, 1994 to July 2011). A review of European and American "grey literature" databases (NTIS, SIGLE) were also conducted. The terms and medical subject headings $(\mathrm{MeSH})$ used in retrieving citations were "schistosom" (" means the inclusion of all words with the preceding radical), "praziquantel", "artemisinin", "artemether", "artesunate", "chemotherapy". The retrieval formula was: schistosom* AND (praziquantel OR artemether OR artesunate). The searches were performed mainly in Chinese and English with a limitation to human participants. One reviewer (LR) identified relevant studies by screening titles and abstracts; a manual search was performed systematically using the authors' reference lists. The full-texts of potentially relevant studies were further evaluated by three reviewers (RL, HFD and YG).

\section{Criteria of inclusion and exclusion}

The inclusion criteria were: (i) independent studies assessing the antischistosomal efficacy of PZQ, AM and AS, administrated alone or in combination for human schistosomiasis treatment and prevention; (ii) the year of the study conducted or published was reported; (iii) the sample size was reported; (iv) the same drugs' efficacy evaluation indicators between experimental populations and control populations, i.e. reporting parasitological outcome eggs-positive or eggs-negative by Kato-Katz thick stool smears technique and/or miracidia hatching tests for detecting eggs of S. japonicum, S. mansoni, and S. mekongi or urine filtration for detecting eggs of S.haematobium after approximately 3-4 weeks post-treatment, which was recommended as the 
standard method for schistosomiasis parasitological diagnosis by WHO in 1980 [10]; or reporting emergence or absence of acute schistosomiasis in the trials of assessing some drug's efficacy in controlling morbidity; (v) the studies were either randomized controlled trials (RCTs) or non-randomized control trials (nRCTs); (vi) with raw data which could be changed into relative risk (RR) and 95\% CI RR and 95\% CI were reported.

Exclusion criteria were: (i) study participants were not human; (ii) without control group; (iii) incomplete information; (iv) duplicate publications; (v) studies described only results without detailed background and method introduction; (vi) reviews. Figure 1 summarizes the studies selection process.

\section{Data extraction and methodological/quality assessment} The following information was independently extracted by two reviewers (RL and YG) and was checked together, discrepancies were solved through discussion. The extracted information included: first author's name and year of publication, test sites (i.e. where trials were implemented), time (i.e. when trials were implemented), participants, schistosoma species, interventions, diagnostics methods, follow-up time, raw dichotomous data of efficacy assessment (NO. of positive/NO. of diagnosed), RRs and their 95\% CIs, type of study design (RCT or $\mathrm{nRCT}$ ), and intervention purposes (prevention or treatment).
The quality of included RCTs was assessed by examining whether there is randomization, blinding, and information about follow-up and dropouts/withdrawals of participants according to the guidance of the methodological quality assessment of RCTs in the Cochrane Handbook for Systematic Reviews of Interventions 4.2.6 and the Jadad scoring criteria [22,23]. The score for quality scale ranges from 0 to 5 points, the higher the score, the higher the quality of trial; and a trial with a Jadad score $\geq 3$ has been considered to be of ample quality.

\section{Diseases, interventions and outcomes}

Schistosomiasis japonica, schistosomiasis mansoni, schistosomiasis haematobia, and schistosomiasis mekongi were included in this meta-analysis. The participants included schoolchildren, villagers, schistosomiasis patients, fishermen, and people or soldiers participating in fighting against floods.

The participants of experimental groups took antischistosomal drugs such as PZQ, AM, or AS alone or in combination for treatment (to remove the adult worms from schistosomiasis patients by $\mathrm{PZQ}$ ) or prevention (to control morbidity in high-risk population by ART or PZQ). Control groups took the same dose of placebo or PZQ (of the combination therapy trials) or nothing. The chemotherapeutic outcome evaluation was parasitological cure, which was defined as eggs-positive or eggs-

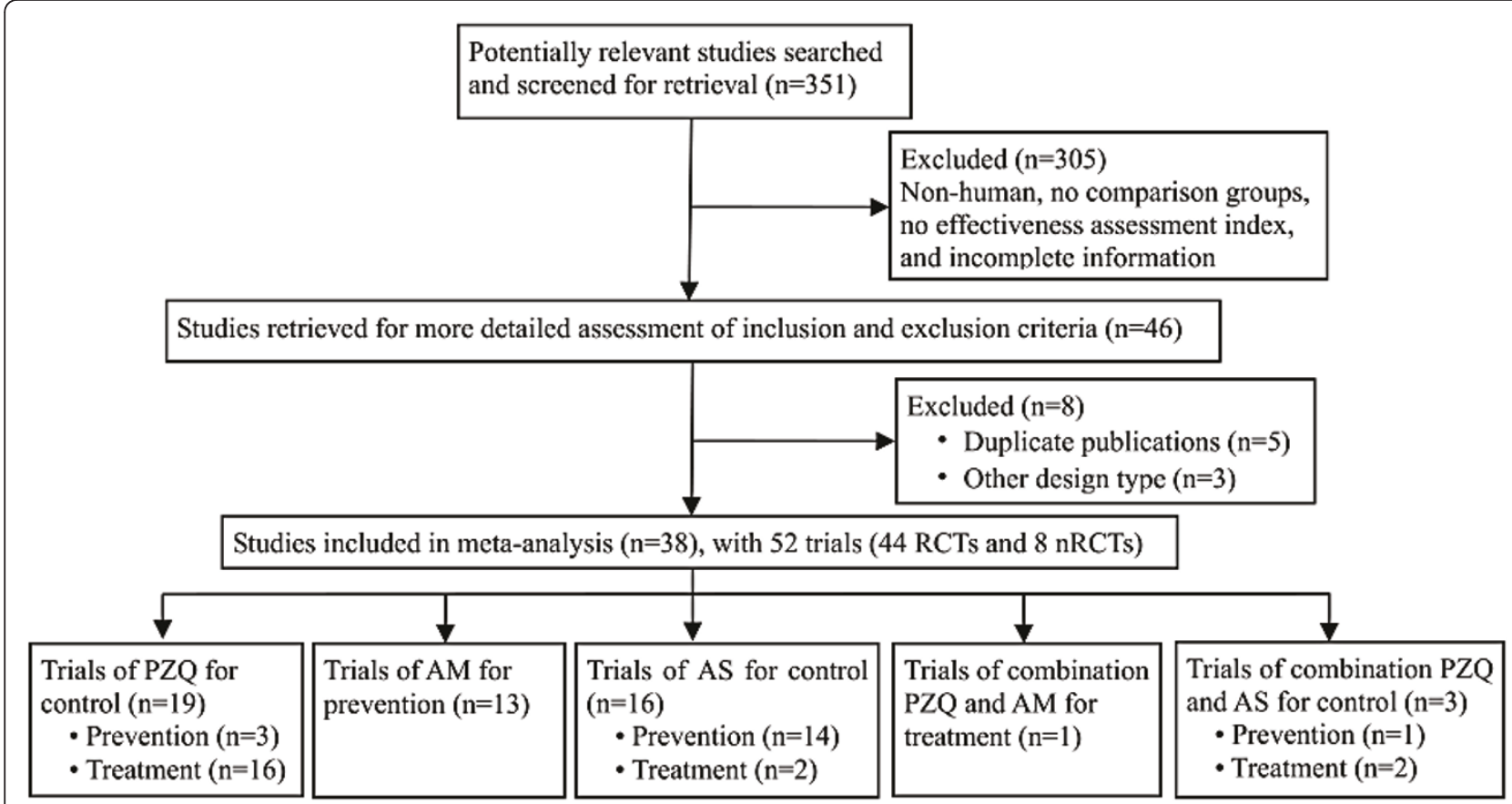

Figure 1 Flow diagram showing the articles selection process for present meta-analyses of the efficacy of PZQ and ART (AM and AS) administrated alone or in combination for human schistosomiasis treatment or prevention. Individual searches don't add up to 351 because some articles could be found simultaneously in multiple literature databases. 
negative, or emergence or absence of acute schistosomiasis symptoms.

\section{Data synthesis and statistical analysis}

Meta-analyses were conducted in categories of PZQ, $\mathrm{AM}$, or AS alone and in combination, respectively. RRs based on dichotomous data were set as statistical indicators. Subgroup analyses were conducted according to different design types, schistosoma species, time of medication and dosages. The protection rates were calculated based on the summary RRs. All the statistical analysis work was performed using the statistical package Review Manager 4.3 software (Cochrane Collaboration, Oxford, UK) and Stata/SE 11 (Stata ${ }^{\circledR}$ Corporation, Texas, USA) for Egger's publication bias test by LR. The fixed-effects model was used to combine study-specific RRs, when there was no significant heterogeneity among studies. Otherwise, the random-effects model was used.

\section{Publication bias and sensitivity analysis}

In order to examine the reliability and stability of our meta-analyses, publication bias was assessed by means of both funnel plot (qualitative) and Egger's publication bias test (quantitative). In addition, sensitivity analysis was performed by excluding some trials with different schistosome species (as the parasitological diagnosis method used for S. haematobium is different from that of other species) or with larger sample size.

\section{Results}

\section{Studies selected}

Overall, 38 articles with 52 trials met the inclusion criteria and were finally used for this meta-analysis. Figure 1 shows the studies' selection process: 19 trials on PZQ's efficacy evaluation (9 RCTs and $7 \mathrm{nRCTs}$ on treatment, 2 RCTs and 1 nRCT on prevention) [24-37]; 12 RCTs on AM's efficacy for prevention [38-49]; 16 RCTs on AS's efficacy (14 RCTs for prevention and 2 RCTs for treatment) [24,30,50-59], 6 RCTs out of Zhang et al.'s study [55] of AS's efficacy in preventing $S$. japonicum infections reported the duplications of studies from Liu et al. [58], Yi et al. [56], Xu et al. [50,51], and Liu et al. [57] and were excluded; one RCT on PZQ and $\mathrm{AM}$ in combination for treatment [60]; 3 RCTs on PZQ and AS in combination (2 RCTs for treatment and one for prevention) $[24,30,61]$. A number of 5 studies contained 2 or more independent trials $[34,35,37,38,55]$. Further 5 studies [62-66] were excluded for duplicate publication, and 3 studies for different design types [67-69].

\section{Study characteristics and methodological quality}

Studies were conducted in areas that are endemic for human schistosomiasis, including Nigeria, Burkina Faso,
Niger, KwaZulu/Natal of South Africa, Côte d'Ivoire, Gabon, Philippines, Tanzania, Brazil, and China (see Additional file 1, Table S1). PZQ dosages applied ranged from a single oral dose of $30-60 \mathrm{mg} / \mathrm{kg}$ or divided (2-3) dosages in RCTs-designed studies, and only one trial reported about participants who had received a single oral dose of PZQ at $20 \mathrm{mg} / \mathrm{kg}$ [35]. For nRCTs about PZQ's efficacy, there were several types of drug administration i.e. a single oral dose of $40 \mathrm{mg} / \mathrm{kg}$ or $60 \mathrm{mg} / \mathrm{kg}$, multiple (2-3) oral doses of the same concentrations, two doses of $40 \mathrm{mg} / \mathrm{kg}$, and two doses of $30 \mathrm{mg} / \mathrm{kg}$ added by another dose of $40 \mathrm{mg} / \mathrm{kg}$. The dosage of AM given was $6 \mathrm{mg} / \mathrm{kg} /$ day, ranging from 2 doses to 13 doses over about 15-day intervals, 3-week intervals, or one-month interval, for preventing schistosomiasis morbidity. AS was applied by two medication types, $4 \mathrm{mg} /$ $\mathrm{kg} /$ day over 3 consecutive days for treatment, or 3-14 doses of $6 \mathrm{mg} / \mathrm{kg} /$ day over 1 - or 2-weeks intervals for prevention. For PZQ and AM in combination participants of the experimental group received a single oral dose of $60 \mathrm{mg} / \mathrm{kg}$ PZQ and $6 \mathrm{mg} / \mathrm{kg} /$ day AM [60]; for PZQ and AS in combination for treating schistosomiasis haematobia, participants received a single oral dose of $40 \mathrm{mg} / \mathrm{kg}$ PZQ and a dose of $4 \mathrm{mg} / \mathrm{kg} /$ day AS $[24,29]$. Participants in the control groups received just a single oral dose of 40 or $60 \mathrm{mg} / \mathrm{kg}$ PZQ and AM placebo or AS placebo. In another study with PZQ and AS in combination to treat schistosomiasis japonica by soldiers participating in fighting against floods, participants of the experimental group received $1200 \mathrm{mg}$ PZQ once divided into two doses and AS $300 \mathrm{mg}$ once for every 7 days, participants in the control group received nothing [61]. The follow-up time post-treatment differed from studies ranging from 2 weeks to more than 2 years, most of which ranged from 4 weeks to half a year. Table 1 summarizes the Jadad scores of the included RCTs. Among the 29 RCT-designed studies, only 5 studies $[29,40,41,43,51]$ have described the randomization method; one study [37] did not include blinded allocation or outcome measurements, and 11 studies $[24,38,43,49,51-55,57,58]$ had no description of withdrawals or dropouts. Thus 28 of the included RCTs were rated as providing good methodological quality based on a Jadad score of 3-5, and only one study [37] had a Jadad score of 2 . The nRCTs without quality assessment were analyzed separately from the RCTs.

\section{Meta-analysis}

Compared to results using a placebo, a single dose of $30-60 \mathrm{mg} / \mathrm{kg}$ PZQ provided a protection rate of $76 \%$ (95\% CI: $67 \%-83 \%$ ) for treatment of schistosomiasis japonica, which was higher as point estimation than its protection rate against schistosomiasis haematobia [72\% (95\% CI: $65 \%-78 \%)]$ or schistosomiasis mansoni [70\% 
Table 1 Assessment of methodological quality of the included RCTs by Jadad scoring criteria*

\begin{tabular}{|c|c|c|c|c|}
\hline Trial & Randomized $\dagger$ & Double-blinded§ & A description of withdrawals or dropouts & Jadad score \\
\hline Inyang-Etoh PC, 2009 & 1 & 2 & 0 & 3 \\
\hline Borrmann S, 2001 & 2 & 2 & 1 & 5 \\
\hline Santos AT, 1979 & 1 & 2 & 1 & 4 \\
\hline McMahon JE, 1979 & 1 & 1 & 1 & 3 \\
\hline Katz N, 1979 & 1 & 2 & 1 & 4 \\
\hline Liu ZG, 1997 & 1 & 0 & 1 & 2 \\
\hline Song Y, 2006 & 1 & 2 & 0 & 3 \\
\hline Li YS, 2005 & 1 & 2 & 1 & 4 \\
\hline N'Goran EK, 2003 & 2 & 2 & 1 & 5 \\
\hline Utzinger J, 2000 & 2 & 2 & 1 & 5 \\
\hline Tian ZY, 1999 & 2 & 2 & 0 & 4 \\
\hline Huang AS, 1999 & 1 & 2 & 1 & 4 \\
\hline Song Y, 1998 & 1 & 2 & 1 & 4 \\
\hline Xu MS, 1997 & 1 & 2 & 1 & 4 \\
\hline Tian ZY, 1997 & 1 & 2 & 1 & 4 \\
\hline Wang JL, 1997 & 1 & 2 & 1 & 4 \\
\hline Xiao SH, 1996 & 1 & 2 & 0 & 3 \\
\hline Xiao SH, 1995 & 1 & 2 & 1 & 4 \\
\hline Xu MS, 2001 & 1 & 2 & 0 & 3 \\
\hline Cui JF, 2001 & 1 & 2 & 0 & 3 \\
\hline Sun MX, 2000 & 1 & 2 & 0 & 3 \\
\hline Zhang SJ, 2000 & 1 & 2 & 0 & 3 \\
\hline Yi ZH, 2000 & 1 & 2 & 1 & 4 \\
\hline Liu HY, 1999 & 1 & 2 & 0 & 3 \\
\hline Xu MS, 1998 & 2 & 2 & 0 & 4 \\
\hline Liu ZD, 1996 & 1 & 2 & 0 & 3 \\
\hline Xu MS, 1996 & 1 & 2 & 1 & 4 \\
\hline Wu LJ, 1995 & 1 & 2 & 1 & 4 \\
\hline Hou XY, 2008 & 1 & 2 & 1 & 4 \\
\hline
\end{tabular}

* Range 0 5 (the higher the Jadad score is, the higher the quality of study is).

† Represents generation of allocation sequence.

$\S$ Represents allocation concealment.

(95\% CI: 25\%-88\%)]. But, the differences of protection rates among the three species are of no statistical significance with regard to their $95 \%$ CIs, and their overall pooled protection rate is $73 \%$ (95\% CI: $67 \%-78 \%$ ); meanwhile, the increasing dosage within $30-60 \mathrm{mg} / \mathrm{kg}$ gives no significant improvement in efficacy. Compared to this, $20 \mathrm{mg} / \mathrm{kg}$ PZQ seems to be less effective resulting in a protection rate of just 16\% (95\% CI: $-81 \%-61 \%)$. For PZQ's efficacy during nRCTs, dosages of $60-100 \mathrm{mg} / \mathrm{kg}$ (i.e. $60 /(40 \times 2$ doses $) /(30 \times 2$ doses +40$) \mathrm{mg} / \mathrm{kg})$ provide better efficacies than a single dose at $40 \mathrm{mg} / \mathrm{kg}$, their protection rates were 91\% (95\% CI: 88\%-92\%) vs. 52\% (95\% CI: 49\%-55\%), respectively. In addition, several doses of PZQ at $40 \mathrm{mg} / \mathrm{kg}$ of both two RCTs and one nRCT produced great effects on preventing schistosomiasis morbidity, their protection rates were 98\% (95\% CI: $93 \%-99 \%)$ and $100 \%$, respectively. Multiple (6-7) doses of $6 \mathrm{mg} / \mathrm{kg}$ AM applied in 1-month intervals resulted in protection rates of $24 \%$ (95\% CI: $8 \%-37 \%)$ with respect to preventing S. japonicum infections, which increased to $50 \%$ (95\% CI: $29 \%-65 \%)$ when the time interval was shortened to 3-week intervals; 4-7 doses of $6 \mathrm{mg} /$ $\mathrm{kg}$ AM applied in 15-day intervals led to protection rates of $65 \%$ (95\% CI: 50\%-76\%) in preventing S. japonicum infections, which increased significantly to $90 \%$ (95\% CI: 79\%-95\%) when the dosages were increased to 8-13 doses. In addition, 2-3 doses of $6 \mathrm{mg} / \mathrm{kg} \mathrm{AM}$ with 15-day intervals produced great effects on preventing against $S$. japonicum infection in persons of short term exposure, who e.g. participated in fighting against floods, here, the protection rate was $91 \%$ (95\% CI: 76\%-97\%). 3 doses of $6 \mathrm{mg} / \mathrm{kg}$ AS given during 1 -week intervals used to prevent $S$. japonicum infection resulted in protection rates of $89 \%$ (95\% CI: $55 \%-97 \%$ ), which rose to $97 \%$ (95\% CI: $88 \%-99 \%)$ when the dosages increased to 8 doses; 3-5 doses of $6 \mathrm{mg} / \mathrm{kg}$ AS applied in 2-week intervals used to prevent S. japonicum 
infection led to a protection rate of 71\% (95\% CI: 48\%$84 \%$ ), which rose significantly to $95 \%$ (95\% CI: 91\%-97\%) when the dosages increased to 8-14 applications. Two studies showed no significant effects of AS treatments compared to a placebo, with a protection rate of $45 \%$ (95\% CI: $-78 \%-83 \%$ ) which spanned across zero. PZQ and ART (AM or AS) in combination used for schistosomiasis treatment resulted in a better efficacy than PZQ treatment alone, with a pooled RR of 0.61 (95\% CI: 0.39-0.96) and a protection rate of $39 \%$ (95\% CI: 4\%-61\%), which was converted to $84 \%$ (95\% CI: 64\%-91\%) after the control PZQ was transformed into placebo based on the RCTs' result of PZQ at $30-60 \mathrm{mg} / \mathrm{kg}$ for treatment. PZQ and AS in combination had a great effect on prevention against $S$. japonicum infection with a protection rate of $96 \%$ (95\% CI: 78\%99\%). All of these results are summarized in detail in Figure 2, 3, 4 and 5 and Table 2.

\section{Publication bias and sensitivity analysis}

Funnel plots and Egger's test results of publication bias estimation of each subgroup based on study-specific RRs showed that in most subgroups the included trials are almost evenly distributed around the vertical axis of pooled RR and within the 95\% CI of pooled log RR (Figures $6,7,8$ and 9). This indicated that no evidence of a publication bias exists, except for the subgroup RCTsdesigned of 8-13 doses of $6 \mathrm{mg} / \mathrm{kg}$ AM during 15 dayintervals used for prevention against $S$. japonicum infection. The $P$ value of Egger's test was 0.01 , which indicated that a publication bias may exist. In addition, sensitivity analyses indicated there were no significant changes in the results of RRs' estimation and their 95\% CIs between the restricted data sets and their combined overall values in each subgroup (Table 3 ). Thus the results of our meta-analyses are stable and credible.

\section{Adverse effects}

Adverse effects were reported for people who had taken PZQ for treatment or prevention against schistosomiasis. Among those were dizziness, stomach discomfort or stomach ache, headache, nausea, debility, muscular and joint soreness, and diarrhoea, which disappeared shortly after drug withdrawal [70,71]. In the trials of Tian et al. [42], Song et al. [38,45], Xu et al. [46], Wang et al. [47]

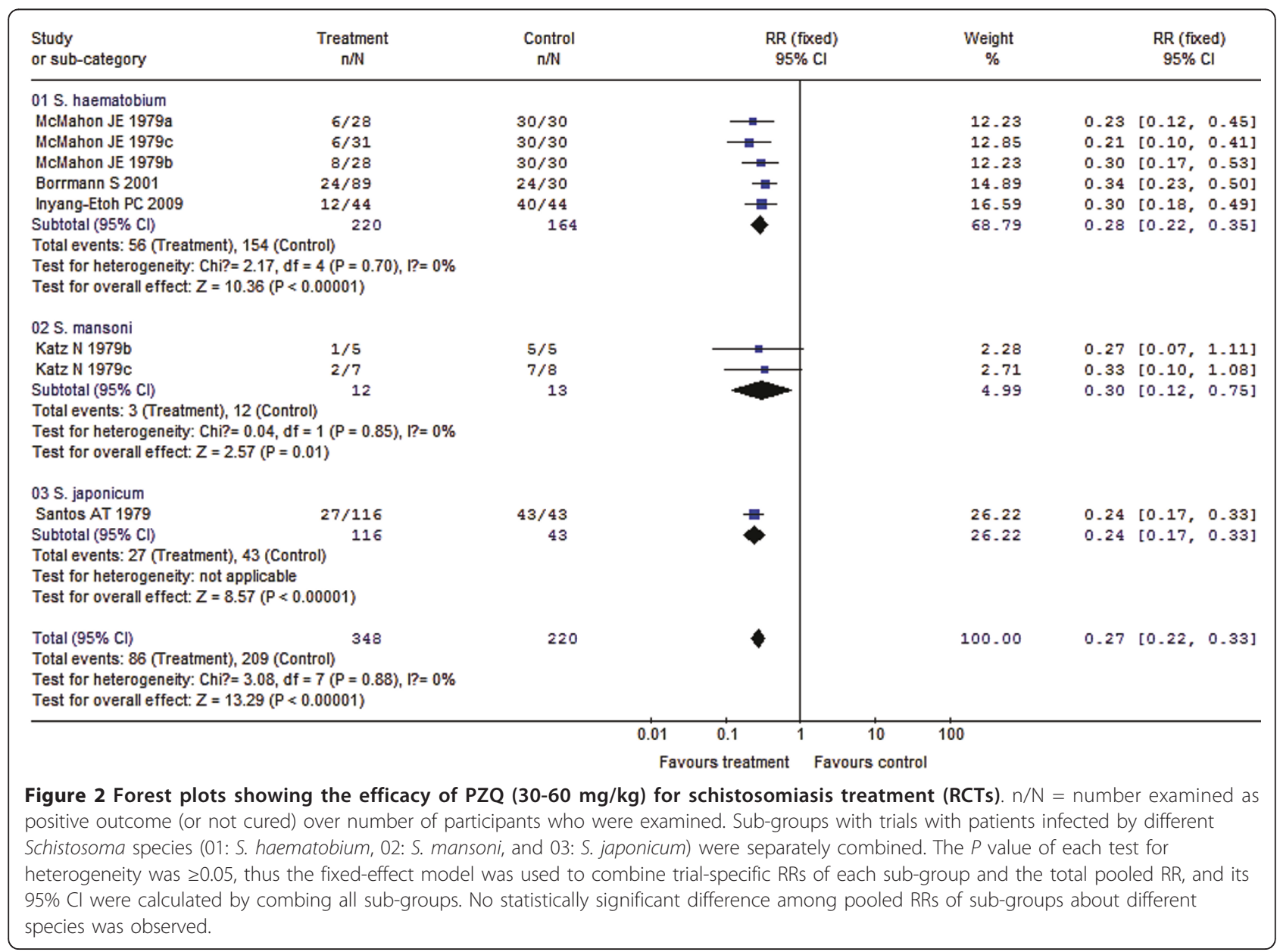




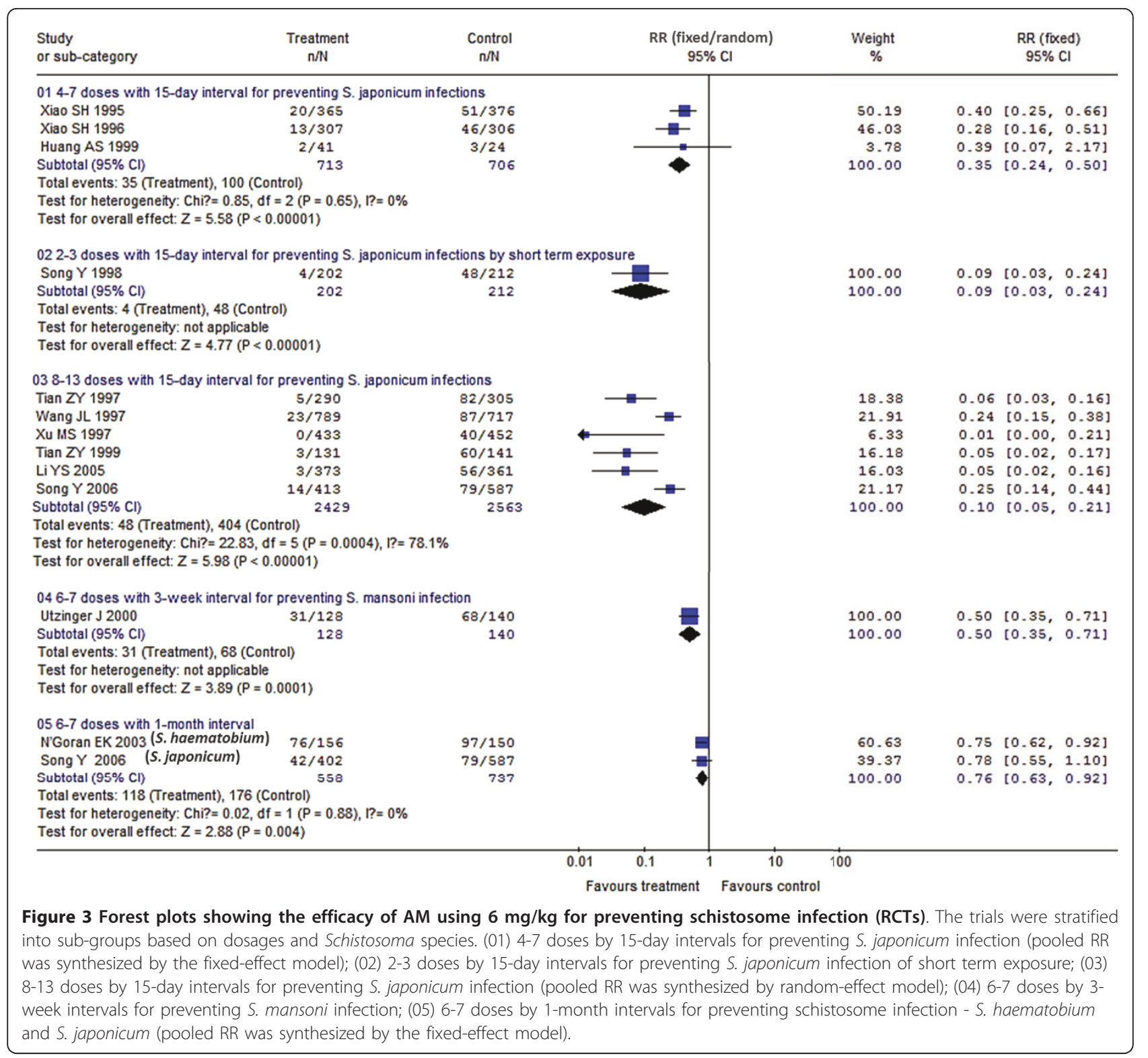

and Xiao et al. $[48,49]$ about assessing the efficacy of $\mathrm{AM}$ in preventing against $S$. japonicum in the regions of Anhui, Hunan, Jiangxi and Yunnan provinces, only a few of total 4, 754 participants aged from 5 to 60 years old experienced symptoms of mild and transient dizziness, headache, and abdominal pain symptoms with good tolerance and less severe adverse effects [72,73]. AS was also reported being well tolerable. Only about $1 \%$ of the participants reported about mild abdominal pain, dizziness, headache and diarrhoea, or slight fever [59].

\section{Discussion}

PZQ was synthesized by Bayer and Merck in Germany in 1972 [74], and introduced for clinical use in the
People's Republic of China since 1978 [74,75]. Today, PZQ is the most frequently used drug for schistosomiasis treatment in endemic areas, and regularly used also in large scale programmes [76]. PZQ exhibits stage-specific functions in killing adult worms $[73,77,78]$. Our meta-analysis showed that a single oral dose of 30-60 $\mathrm{mg} / \mathrm{kg}$ PZQ or $40 / 60 \mathrm{mg} / \mathrm{kg}$ divided in two doses during RCTs resulted in protection rates of $73 \%$ (95\% CI: $67 \%-$ $78 \%$ ) for treating schistosomiasis. No significant differences were observed among the species S. haematobium, $S$. japonicum and S. mansoni, but the protective efficacy decreases significantly to $16 \%$ (95\% CI: $-81 \%-61 \%)$ when the PZQ dosage decreased to a single dose of $20 \mathrm{mg} / \mathrm{kg}$. Similarly, $60-100 \mathrm{mg} / \mathrm{kg}$ PZQ (i.e. $60 \mathrm{mg} / \mathrm{kg}$ as single or double treatment, two doses of $40 \mathrm{mg} / \mathrm{kg}$, or two doses 


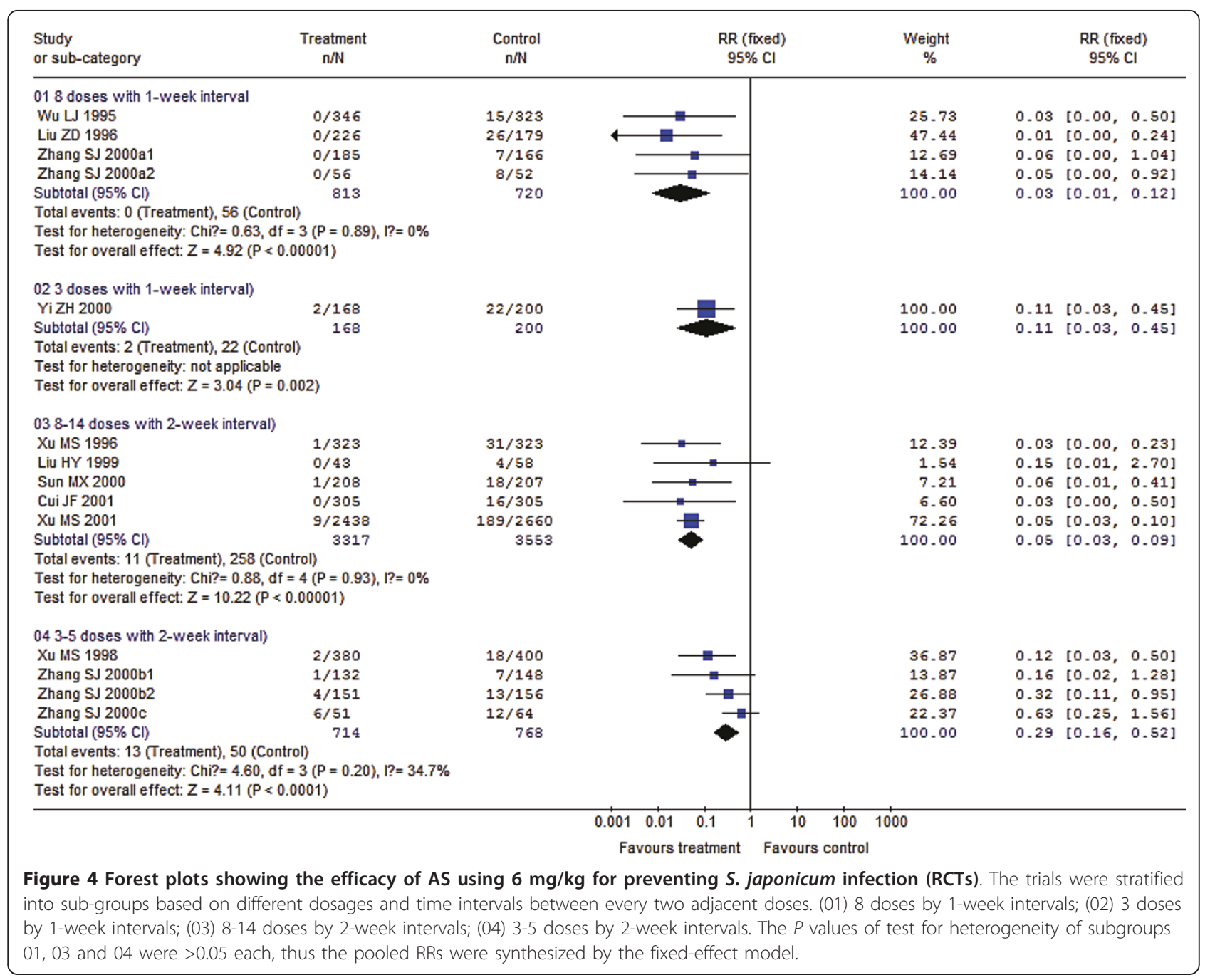

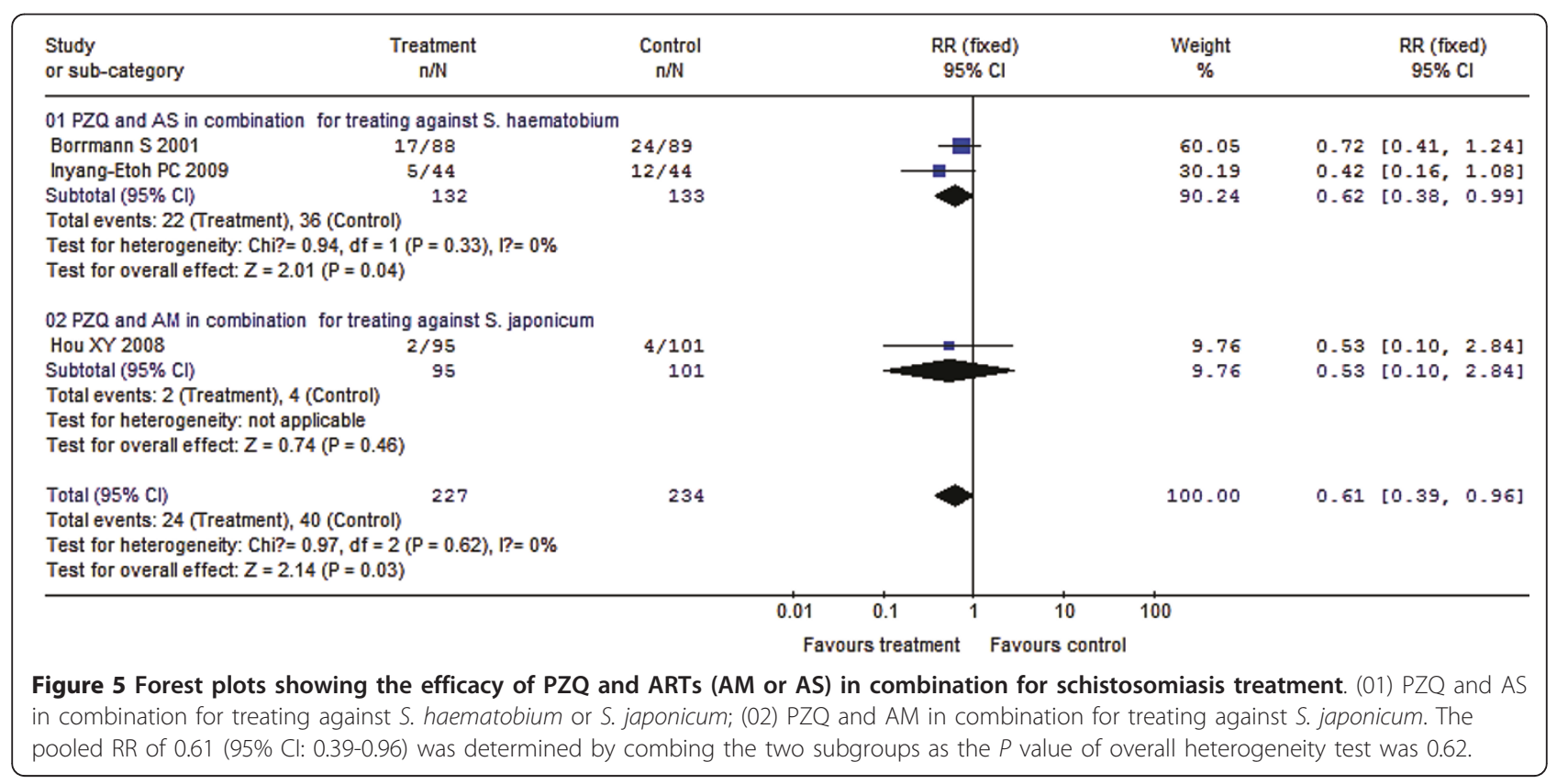


Table 2 Estimates of summary RRs and protection rates of the antischistosomal drugs' efficacy

\begin{tabular}{|c|c|c|c|c|c|}
\hline Studies included & $\begin{array}{c}\text { Trials } \\
(\mathbf{n})^{*}\end{array}$ & $\begin{array}{l}\text { Participants } \\
\left(\mathrm{N}_{1} / \mathrm{N}_{2}\right)^{\Delta}\end{array}$ & $\begin{array}{l}\text { Pooled RRs } \\
(95 \% \mathrm{CI})^{\wedge}\end{array}$ & $\begin{array}{l}\text { Protection rates } \\
\quad \%(95 \% \mathrm{Cl})\end{array}$ & $\begin{array}{l}\text { Heterogeneity } \\
\text { test, } P \text { values }\end{array}$ \\
\hline PZQ for treatment & 16 & $4108 / 5331 \S$ & - & - & - \\
\hline - RCT designed (20 mg/kg) against S. mansoni & 1 & $4 / 2$ & $\begin{array}{l}0.84(0.39, \\
1.81)\end{array}$ & $16(-81,61)$ & - \\
\hline • RCT designed (30-60 mg/kg) & 8 & $348 / 220$ & $\begin{array}{l}0.27(0.22 \\
0.33)\end{array}$ & $73(67,78)$ & 0.88 \\
\hline ·S. haematobium & 5 & 220/164 & $\begin{array}{l}0.28(0.22 \\
0.35)\end{array}$ & $72(65,78)$ & 0.70 \\
\hline -S. mansoni & 2 & $12 / 13$ & $\begin{array}{l}0.30(0.12 \\
0.75)\end{array}$ & $70(25,88)$ & 0.85 \\
\hline •S. japonicum & 1 & $116 / 43$ & $\begin{array}{l}0.24(0.17 \\
0.33)\end{array}$ & $76(67,83)$ & - \\
\hline • nRCT designed (40 mg/kg) & 3 & $2375 / 2847$ & $\begin{array}{l}0.48(0.45 \\
0.51)\end{array}$ & $52(49,55)$ & $<0.01$ \\
\hline - $n R C T$ designed $(60 /(40 \times 2) /(30 \times 2+40) \mathrm{mg} / \mathrm{kg})$ & 4 & $1381 / 2262$ & $\begin{array}{l}0.09(0.08 \\
0.12)\end{array}$ & $91(88,92)$ & 0.17 \\
\hline PZQ for prevention against $S$. japonicum & 3 & $2405 / 121$ & - & - & - \\
\hline$\cdot \mathrm{RCT}$ designed & 2 & $155 / 61 \S$ & $\begin{array}{l}0.02(0.01 \\
0.07)\end{array}$ & $98(93,99)$ & 0.15 \\
\hline • nRCT designed & 1 & $2250 / 60$ & $\begin{array}{l}0.00(0.00 \\
0.00)\end{array}$ & 100 & - \\
\hline AM for prevention (6 mg/kg) (RCTs) & 13 & $4030 / 3771 \S$ & - & - & - \\
\hline $\begin{array}{l}\cdot 2-3 \text { doses by } 15 \text {-day interval against } S \text {. japonicum by short } \\
\text { term exposure during fighting against floods }\end{array}$ & 1 & 202/212 & $\begin{array}{l}0.09(0.03 \\
0.24)\end{array}$ & $91(76,97)$ & - \\
\hline -4-7 doses by 15-day interval against S. japonicum & 3 & $713 / 706$ & $\begin{array}{l}0.35(0.24 \\
0.50)\end{array}$ & $65(50,76)$ & 0.65 \\
\hline - 8-13 doses by 15 -day interval against S. japonicum & 6 & $2429 / 2563$ & $\begin{array}{l}0.10(0.05 \\
0.21)\end{array}$ & $90(79,95)$ & $<0.01$ \\
\hline - 6-7 doses by 3-week interval against S. mansoni & 1 & $128 / 140$ & $\begin{array}{l}0.50(0.35 \\
0.71)\end{array}$ & $50(29,65)$ & - \\
\hline $\begin{array}{l}\text { - 6-7 doses by 1-month interval against S. haematobium and } S \text {. } \\
\text { japonicum }\end{array}$ & 2 & $558 / 737$ & $\begin{array}{l}0.76(0.63 \\
0.92)\end{array}$ & $24(8,37)$ & 0.88 \\
\hline AS (6 mg/kg) for preventing S. japonicum infection (RCTs) & 14 & $5012 / 5241$ & - & - & - \\
\hline$\cdot 3$ doses by 1 -week interval & 1 & 168/200 & $\begin{array}{l}0.11(0.03 \\
0.45)\end{array}$ & $89(55,97)$ & - \\
\hline - 8 doses by 1 -week interval & 4 & $813 / 720$ & $\begin{array}{l}0.03(0.01 \\
0.12)\end{array}$ & $97(88,99)$ & 0.89 \\
\hline - 3-5 doses by 2-week interval & 4 & $714 / 768$ & $\begin{array}{c}0.29(0.16 \\
0.52)\end{array}$ & $71(48,84)$ & 0.20 \\
\hline - 8-14 doses by 2-week interval & 5 & $3317 / 3553$ & $\begin{array}{c}0.05(0.03 \\
0.09)\end{array}$ & $95(91,97)$ & 0.93 \\
\hline AS $(4 \mathrm{mg} / \mathrm{kg} \times 3$ doses) for treating S. haematobia (RCTs) & 2 & $132 / 74$ & $\begin{array}{c}0.55(0.17 \\
1.78)\end{array}$ & $45(-78,83)$ & $<0.01$ \\
\hline$P Z Q+A M / A S$ for treatment (RCTs) & 4 & $227 / 234$ & $\begin{array}{c}0.61(0.39 \\
0.96)\end{array}$ & $84(64,91) \dagger$ & 0.62 \\
\hline$\cdot$ PZQ + AM against S. japonicum & 1 & $95 / 101$ & $\begin{array}{l}0.53(0.10 \\
2.84)\end{array}$ & $86(6,98)+$ & - \\
\hline$\cdot$ PZQ + AS against S. haematobium & 2 & $132 / 133$ & $\begin{array}{c}0.62(0.38 \\
0.99)\end{array}$ & $83(62,92)+$ & 0.33 \\
\hline $\mathrm{PZQ}+\mathrm{AS}$ for prevention against S. japonicum (nRCT) & 1 & $1362 / 112$ & $\begin{array}{c}0.04(0.01 \\
0.22)\end{array}$ & $96(78,99)$ & - \\
\hline
\end{tabular}

* There are 39 studies with53 trials included as some of the studies have multiple drugs trials.

$\Delta N_{1} / N_{2}=$ the number of participants in test group/the number of participants in control group.

A Pooled RRs $(95 \% \mathrm{Cl})$ are presented which were calculated by fixed-effects model when $P$ value $\geq 0.05$ of heterogeneity test, and by random-effects model if not.

† Their average protection rates and $95 \% \mathrm{Cl}$ were calculated when the drugs given to the controls were transformed into placebo (based on the RCTs results of PZQ 30-60 mg/kg for treatment).

$\S$ The sum of participants in subgroups doesn't equal the true total because some studies $[35,39,64]$ have the same control participants. 

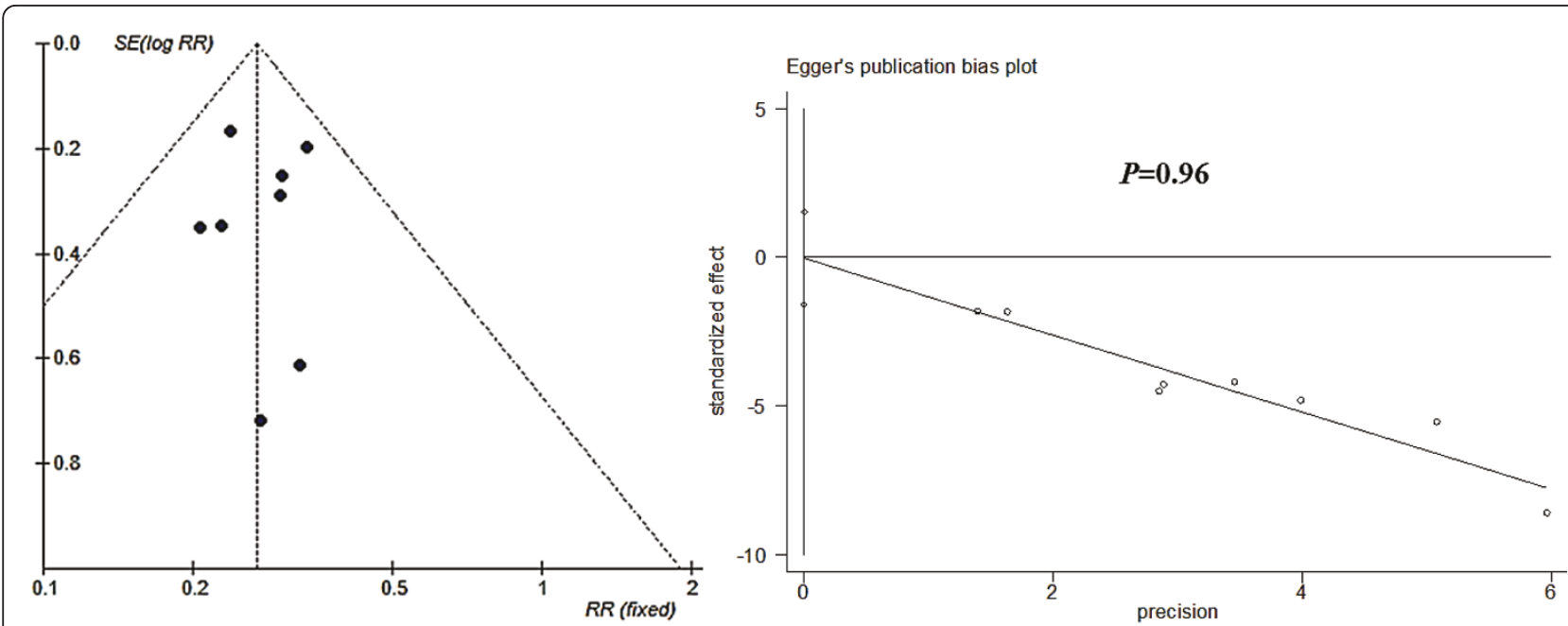

Figure 6 Funnel plot and Egger's publication bias test for RCTs of PZQ's efficacy on schistosomiasis treatment. The pooled log-RR for these trials is shown with a dashed vertical line, and the dashed slash lines distributed in both sides are the cutoff values of $95 \% \mathrm{Cl}$ of pooled $\log$ RR. The Egger's publication bias test showed that no publication bias exists $(P=0.96)$.

of $30 \mathrm{mg} / \mathrm{kg}$ adding a single dose of $40 \mathrm{mg} / \mathrm{kg}$ ) during nRCTs revealed protection rates of 91\% (95\% CI: $88 \%$ $92 \%)$. The protective effect declined significantly to $52 \%$ (95\% CI: $49 \%-55 \%$ ) when the dosage was reduced to a single dose of $40 \mathrm{mg} / \mathrm{kg}$. Thus it can be concluded that multiple doses of $40 / 60 \mathrm{mg} / \mathrm{kg}$ PZQ provide an enhanced efficacy in treating schistosomiasis compared to a single dose. Additionally, when PZQ was applied during the $3^{\text {rd }}-4^{\text {th }}$ week after the first exposure of a patient to infected water harboring schistosome cercariae, is turned out to be also effective in preventing acute schistosomiasis morbidity with a protections rate of $98 \%$ (95\% CI: $93 \%-99 \%$ ) in two RCTs, and $100 \%$ of one
nRCT [36,62]. Temporal observations and long-term follow-up investigations about adverse effects showed that PZQ had low toxicity, mild adverse symptoms, no malformation effects, and no sequel. The incidence rates of heavy side-effects were between $0.47 \%$ and $1.54 \%$ [79]. Thus PZQ has been a safe and effective antischistosomal drug with a broad applicability for all species of schistosome $[35,80]$.

One key issue of chemotherapy for human schistosomiasis treatment is the concern of investigators and clinicians for the emergence of PZQ resistance [81-83]. To date, there is no convincing clinical evidence for schistosome resistance to PZQ used for human
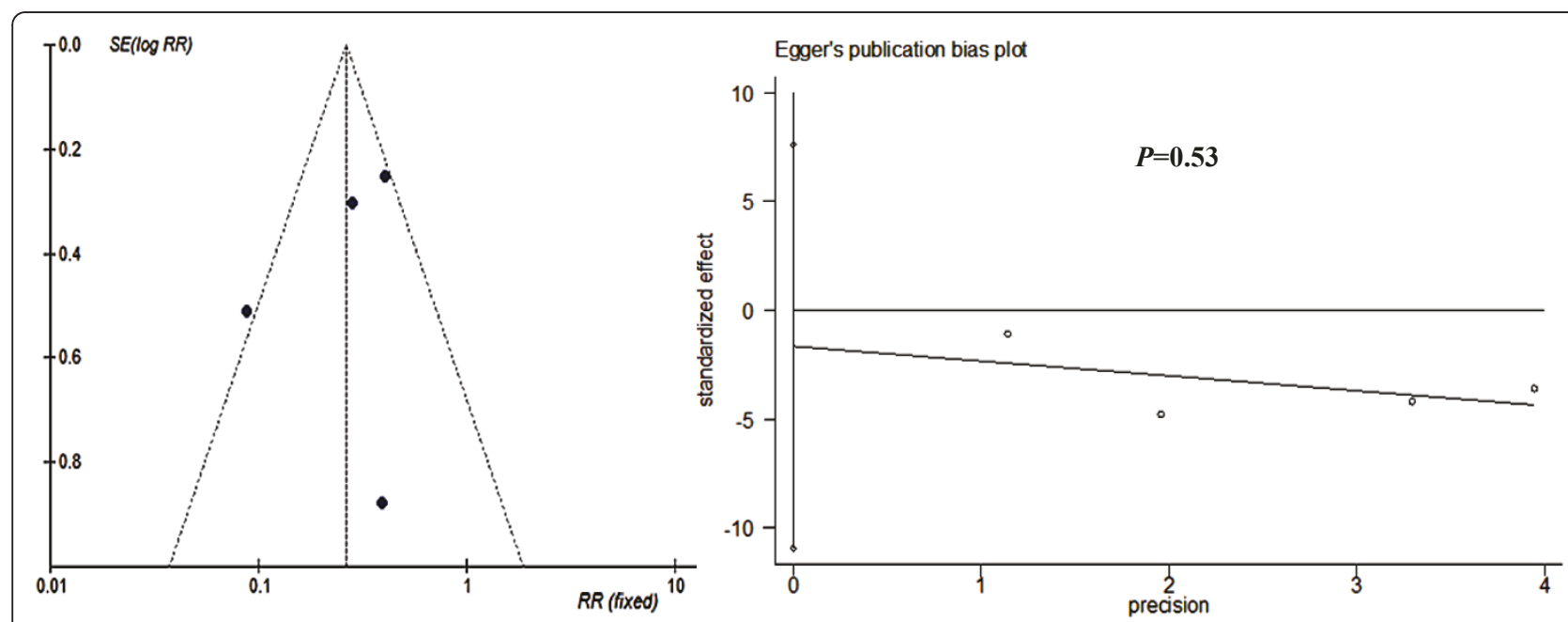

Figure 7 Funnel plot and Egger's publication bias test for RCTs (2-7 doses by 15-day intervals) of AM's efficacy on preventing S. japonicum infection. There is one point (representing one trial) outside the cutoff values of $95 \% \mathrm{Cl}$ of pooled log RR. The Egger's publication bias test showed that no publication bias exists $(P=0.53)$. 

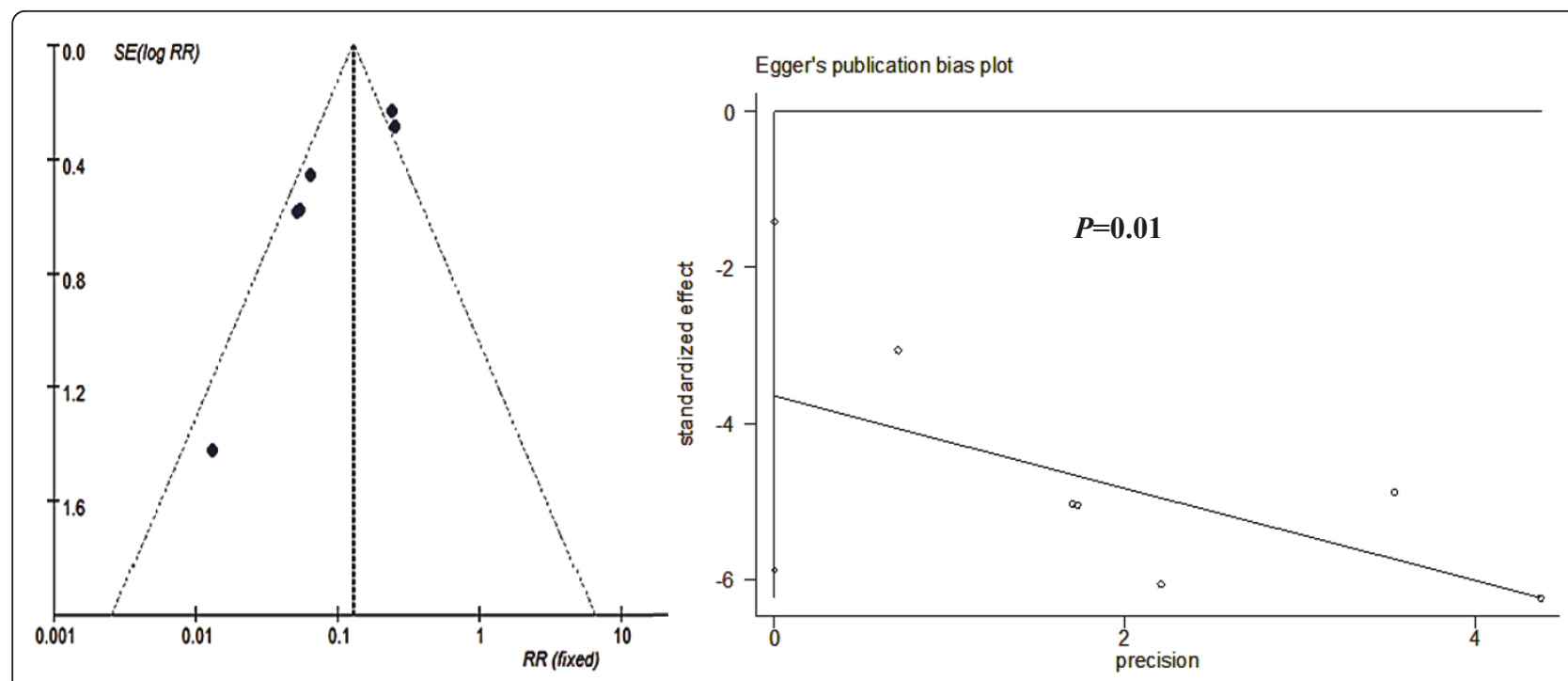

Figure 8 Funnel plot and Egger's publication bias test for RCTs (8-13 doses in 15-day intervals) of AM's efficacy on preventing S. japonicum infection. There are two points (represented two trials) distributing outside the cutoff values of $95 \% \mathrm{Cl}$ of pooled log RR. The Egger's publication bias test showed that a publication bias may exist $(P=0.01)$.

schistosomiasis treatment, although worrying low-cure rates have been reported in some studies [84-93]. Our meta-analysis covering a publication period from 1979 to 2009 indicated that PZQ is still effective for S. haematobium, S. mansoni and S. japonicum with negligible variations. We conclude that there is no reason to be worried about the spreading of extensive and serious PZQ resistance, which as King et al. mentioned in 2000 "... will likely take 10 or more years to emerge" [94]. However, one should not lose sight of first evidence for reports indicating the existence of PZQ-tolerable schistosomes which have emerged locally in some African areas [90]. The observed variations between the results of RCTs and nRCTs are explained by the slack design of these nRCTs'. However, dose response trends are the same in RCTs and nRCTs, i.e. larger dosage or more treatment time points increase PZQ's efficacy.

$\mathrm{AM}$ and AS, the derivatives of artemisinin (ART), which was first extracted from the sweet wormwood herb Artemisia annua by Chinese chemist Youyou Tu and her team in 1970s, were at first used for the treatment of malaria (http://www.laskerfoundation.org/

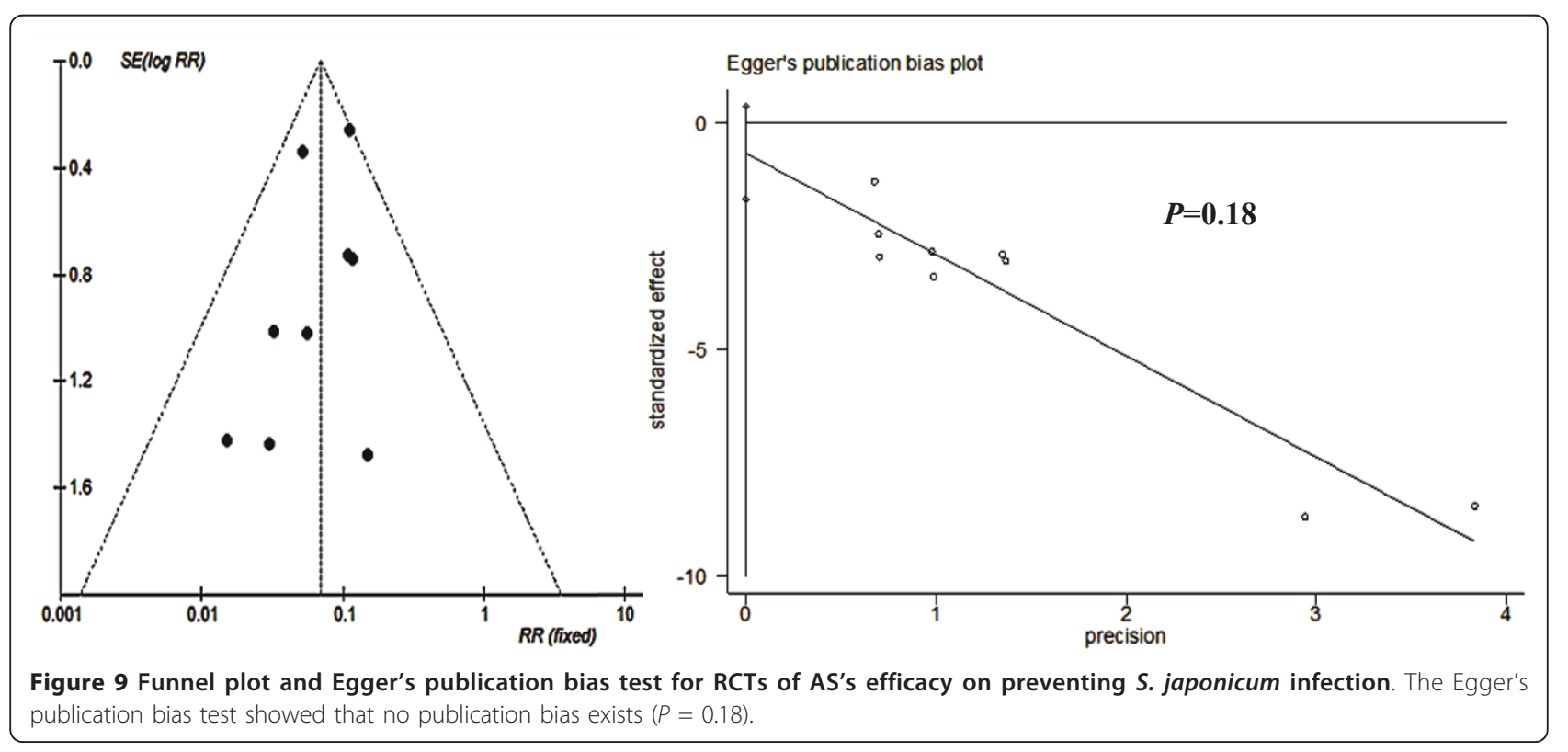


Table 3 Sensitivity analysis of the efficacy of drugs targeting different species of schistosome (RCTs only)

\begin{tabular}{|c|c|c|c|c|c|}
\hline Study & Method* & $\begin{array}{l}\text { No. of } \\
\text { Trials }\end{array}$ & $\begin{array}{l}\text { Participants }\left(\mathrm{N}_{1} /\right. \\
\left.\mathrm{N}_{2}\right)\end{array}$ & $\begin{array}{l}\text { Pooled RRs }(95 \% \\
\text { Cl) }\end{array}$ & $\begin{array}{c}\text { Heterogeneity Test }(P \\
)\end{array}$ \\
\hline & A & 8 & $348 / 220$ & $0.27(0.22,0.33)$ & 0.88 \\
\hline \multirow[t]{3}{*}{ PZQ (RCTs) for treatment } & B & 7 & 232/177 & $0.28(0.22,0.35)$ & 0.90 \\
\hline & C & 6 & $336 / 207$ & $0.27(0.22,0.32)$ & 0.70 \\
\hline & D & 5 & $220 / 164$ & $0.28(0.22,0.35)$ & 0.70 \\
\hline \multirow[t]{2}{*}{ AM for prevention (8-13 doses by 15-day interval) } & A & 6 & $2429 / 2563$ & $0.10(0.05,0.21)$ & $<0.01$ \\
\hline & E & 5 & 1996/2111 & $0.12(0.06,0.24)$ & $<0.01$ \\
\hline \multirow{2}{*}{$\begin{array}{l}\text { AS }(6 \mathrm{mg} / \mathrm{kg}) 8 \text { doses by } 1 \text {-week interval for } \\
\text { preventing }\end{array}$} & A & 4 & $813 / 720$ & $0.03(0.01,0.12)$ & 0.89 \\
\hline & $\mathrm{F}$ & 2 & $572 / 502$ & $0.02(0.00,0.14)$ & 0.73 \\
\hline \multirow{2}{*}{$\begin{array}{l}\text { AS }(6 \mathrm{mg} / \mathrm{kg}) 8-14 \text { doses by 2-week interval for } \\
\text { preventing }\end{array}$} & A & 5 & $3317 / 3553$ & $0.05(0.03,0.09)$ & 0.93 \\
\hline & G & 4 & $879 / 893$ & $0.04(0.01,0.14)$ & 0.83 \\
\hline \multirow{2}{*}{$\begin{array}{l}\text { AS ( } 6 \mathrm{mg} / \mathrm{kg} \text { ) 3-5 doses by } 2 \text {-week interval for } \\
\text { preventing }\end{array}$} & A & 4 & $714 / 768$ & $0.29(0.16,0.52)$ & 0.20 \\
\hline & $\mathrm{H}$ & 3 & $334 / 368$ & $0.39(0.20,0.76)$ & 0.39 \\
\hline
\end{tabular}

${ }^{*}$ A: all trials were included in each subgroup, respectively.

B: one trial [34] with S. japonicum species was excluded.

C: two trials [36] with S. mansoni species were excluded.

D: three trials $[34,36]$ were excluded, the remaining with S. haematoium.

E: one trial [47] in which there was zero person positive in the treatment group was excluded.

F: two trials from the same study [56] were excluded.

G: one trial [53] with the largest sample size was excluded.

$\mathrm{H}$ : one trial [52] with the largest sample size was excluded.

awards/2011_c_description.htm); their potential against S. japonicum was first reported in the 1980s $[95,96]$, just some years after the discovery of the antischistosomal properties of artemisinin [97]. ARTs were approved as antischistosomal drugs by the Chinese Ministry of Health in 1990s [74]. AM and AS have similar functions and kill larval worms (schistosomula) of different schistosome species. Thus they have been used as chemoprophylactic drugs against schistosomes and could induce resistance to reinfection [73,74,98]. Our meta-analyses suggest that shortening application intervals could improve their preventive potential. Best efficacies were obtained with 8 or more doses of $6 \mathrm{mg} / \mathrm{kg}$ AM applied with 15-day intervals ([90\% (95\% CI: 79\%-95\%]), or with $6 \mathrm{mg} / \mathrm{kg}$ AS applied with 1-week intervals (97\% [95\% CI: 88\%-99\%]). AS, however, showed poor performance with respect to schistosomiasis treatment [24,29] (Table 2). Thus AM and AS seem to be suitable as chemoprophylactic drugs for preventing schistosomiasis morbidity, but they seem not to be competent for treating schistosomiasis. In clinical studies using AM or AS to prevent schistosomiasis incidence rates of less than $1 \%$ sideeffects were reported $[71,74,99,100]$. Up to now, there haven't been any reports about drug resistance of schistosomes to these two drugs [101-103] besides one exception. Hua et al [104] reported recently that the sensitivity of artesunate against S. japonicum has decreased after 10 years of use in China. The study reported about protection rates obtained after the application of 4 doses of $6 \mathrm{mg} / \mathrm{kg}$ AS given over 3-day intervals between the $1^{\text {st }}$ and the $2^{\text {nd }}$ dose and the $3^{\text {rd }}$ and the $4^{\text {th }}$ dose, A 11-day interval occurred between the $2^{\text {nd }}$ and the $3^{\text {rd }}$ treatment. Surprisingly, the protection rate during that time period was $74.8 \%$, but it fell to $13.5 \%$ when the AS application was changed to 4 doses of 6 $\mathrm{mg} / \mathrm{kg}$ AS given in 1-week intervals. This unexpected result is difficult to reconcile with similar study reports, and because of its not-perfect study design and contradictory statements between study design and drug administration of participants, why it was not included in our meta-analysis. Although the authors concluded that they identified potential artemisinin-derivate-resistance in S. japonicum, we believe, that more rigorous research is needed to confirm this finding [105].

Our meta-analysis showed that PZQ and AS in combination provided similar preventive efficacy than those obtained by AM or AS administrated as single drugs (approximately 90\%-97\%). In conclusion, AM or AS alone have the capacity as prophylactic drugs for schistosomiasis prevention. PZQ and AM or AS in combination for treatment resulted in higher protection rates (84\% [95\% CI: 64\%-91\%]) than PZQ alone (73\% [95\% CI: 67\%-78\%]), respectively. Thus PZQ-ARTs combinations are useful for schistosomiasis patients repeatedly exposed to infected water. It's well known that ARTs are used in large-scale programmes for malaria 
treatment (mostly epidemic in Africa). However, ARTsresistant malarial parasites have been identified and confirmed in some areas [106-108]. Thus using ARTs for schistosomiasis control is not advisable in areas where schistosomiasis and malaria are co-endemic.

One limitation of this meta-analysis is that the diagnostic approaches used to determine parasites were different among the included trials. There were differences between Kato-Katz technique and urine filtration, the number of specimens, and the number of examinations between trials. The former cannot be changed because it is determined by the two kinds of different clinical pathogenesis. The latter can be improved through using a standardized, quality-controlled diagnostic criterion within and between trials. As discussed by Bergquist et al. [109] and Danso-Appiah et al. [110], different diagnostic methods own different sensitivity and specificity, and the same method also owns different sensitivity and specificity for different infection levels and different numbers of specimens, which were called the diagnostic dilemmas. In the current meta-analyses, we tried to stratify the included trials based on their diagnostic approaches and the numbers of specimens and examinations. However, we were restricted doing this since many of the included trials didn't report about the numbers of specimens and examinations for each participant. Thus a unified study design is urgently needed to make the study outcomes more comparable.

The results of the RCTs dealing with PZQ or ART efficacies (using $40 \mathrm{mg} / \mathrm{kg}$ for treatment; 8-13 doses of 6 $\mathrm{mg} / \mathrm{kg}$ AM with 15-day intervals for preventing, and AS for treatment) have $P$ values $<0.05$, which indicates that the studies included in these three subgroups were heterogeneous. We presume that some factors such as e.g. regional variances, participants' differences, or drug dosage differences among these studies, may have contributed to this heterogeneity [111]. RCTs are preferable to be conducted when assessing drug efficacies in order to exclude the influence of such variable factors. Different species of schistosome were thought to have different susceptibility to these drugs, and we stratified the included trials and performed subgroup meta-analysis. Interestingly, the results provided no hint in this direction when different species were used in RCTs using PZQ (30-60 mg/kg for schistosomiasis treatment), AM (6-7 doses of using $6 \mathrm{mg} / \mathrm{kg}$ in 1-month intervals for preventing schistosomiasis), and PZQ + ART combinatory schistosomiasis treatment, in which the three schistosome species $S$. haematobium, S. japonicum and $S$. mansoni were studied (Figures 2, 3 and 5). We conclude that these drugs may be equally effective against these schistosome species, which we confirmed also by the results of sensitivity analysis (Table 3 ).
Publication bias is usually cited as a reason for the lack of validity in meta-analyses [112]. Publication bias can occur when studies that found no significant effect of antischistosomal drugs in schistosomiasis control are less likely submitted and accepted for publication than those with a positive result. The funnel plots of the included trials showed no evidence for publication bias except the subgroup of 8-13 doses of at $6 \mathrm{mg} / \mathrm{kg}$ AM given with 15-day intervals for preventing schistosomiasis. Two points (represented two trials) were outside the cutoff line, and the $P$ value of Egger's publication bias test was 0.01 , implying the existence of publication bias.

Additionally, we had found two Cochrane reviews discussing drugs for human schistosomiasis treatment $[113,114]$, one review examined PZQ, metrifonate and artemisinin derivatives used alone or in combination for treating urinary schistosomiasis, and the other assessed the effects of oxamniquine and praziquantel on treatment against $S$. mansoni. Thus our meta-analysis represents a good complementary data set adding to the results obtained in these studies.

\section{Conclusions}

Facing the fact that an integrated strategy, which emphasizes health education, access to clean water and adequate sanitation, mechanization of agriculture, and fencing of water buffaloes (mainly for schistosomiasis japonica endemic areas), along with mass chemotherapy for both human and livestock, have been suggested to be carried out in parallel to control the infection sources and to stop schistosome transmission [115-118], we strived to conduct this meta-analysis hoping to provide a scientific basis for monitoring and selecting antischistosomal drugs efficiently, which is a crucial job for the schistosomiasis integrated control programme. With respect to the results obtained in our meta-analyses, we recommend to use multiple doses of AM or AS at 6 $\mathrm{mg} / \mathrm{kg}$ given in 1- or 2-week intervals for prevention against schistosome infection during exposure to infected water. PZQ remains effective in schistosomiasis treatment, and multiple doses of PZQ at $30-60 \mathrm{mg} / \mathrm{kg}$ can improve its efficacy. PZQ and AM or AS administrated in combination are more effective than single drug PZQ therapy, which maybe especially suitable for the treatment of patients, who are repeatedly exposed to infected water.

\section{Additional material}

$$
\begin{aligned}
& \text { Additional file 1: Table S1 Summary of the characteristics of the } \\
& \text { included trials in our meta-analyses evaluating antischistosomal } \\
& \text { drugs (PZQ, AM and AS), used alone or in combination, for human } \\
& \text { schistosomiasis treatment or prevention. This table describes the } \\
& \text { extracted characteristics of the included studies: Author, Year; Test sites; } \\
& \text { Time; Participants; Species; Interventions; Diagnostic approach; Follow-up }
\end{aligned}
$$


time; Treated ( $n / N)$; Controlled ( $n / N)$; Relative Risk; (95\%Cl); Design Type; Usage.

\section{List of abbreviations used}

AM: artemether; ARTs: artemisinin derivatives; AS: artesunate; CBM: Chinese Biomedicine Literature Database; CNKI: China National Knowledge Infrastructure; DALYs: disability-adjusted life years; $\mathrm{nRCT}(\mathrm{s})$ : non-randomized controlled trial(s); PZQ: praziquantel; P: prevention; RCT(s): randomized controlled trial(s); RR(s): relative risk(s); Sh: Schistosoma haematobium; Sj: Schistosoma japonicum; T: treatment; yr: years old; $95 \% \mathrm{Cl}(\mathrm{s})$ : 95 percent confidence interval(s).

\section{Acknowledgements}

This work is financially supported by the National Natural Science Foundation of China awarded \#30872202. The funder had no role in study design, data collection and analysis, decision to publish, or preparation of the manuscript, and the content is solely the responsibility of the authors and does not necessarily represent the official views of the NSFC. We sincerely thank the anonymous referees and Prof. Chris Arme for their series of excellent comments and suggestions. We also sincerely thank our friend Prof. Christoph Grevelding (from Justus-Liebig-University Giessen, Giessen, Germany) for his enthusiastic offering help to embellish the language of the revised version.

\section{Author details}

'Department of Medical Parasitology, School of Basic Medical Science, Wuhan University, Wuhan 430071, People's Republic of China. ${ }^{2}$ Department of Epidemiology, School of Public Health, Wuhan University, Wuhan 430071, People's Republic of China.

\section{Authors' contributions}

RL, HFD and MSJ designed this work. RL and YG searched databases, selected studies and abstracted information. RL entered and analyzed data, drafted the manuscript. RL, HFD and YG contributed to the interpretation of results. RL, HFD, MSJ and QPZ contributed to the refinement of the manuscript. RL, HFD and MSJ revised the manuscript. All of authors have read and approved the final version of the manuscript.

\section{Competing interests}

The authors declare that they have no competing interests.

Received: 4 June 2011 Accepted: 17 October 2011 Published: 17 October 2011

\section{References}

1. Chitsulo L, Engels D, Montresor A, Savioli L: The global status of schistosomiasis and its control. Acta Trop 2000, 77:41-51.

2. King CH, Dickman K, Tisch DJ: Reassessment of the cost of chronic helminthic infection: a meta-analysis of disability-related outcomes in endemic schistosomiasis. Lancet 2005, 365:1561-1569.

3. Gryseels B, Polman K, Clerinx J, Kestens L: Human schistosomiasis. Lancet 2006, 368:1106-1118.

4. Utzinger J, Raso G, Brooker S, De Savigny D, Tanner M, Ornbjerg N, Singer BH, N'goran EK: Schistosomiasis and neglected tropical diseases: towards integrated and sustainable control and a word of caution. Parasitology 2009, 136:1859-1874.

5. Mathers CD, Ezzati M, Lopez AD: Measuring the burden of neglected tropical diseases: the global burden of disease framework. PLOS Negl Trop Dis 2007, 1:e114.

6. Hotez PJ, Molyneux DH, Fenwick A, Kumaresan J, Sachs SE, Sachs JD, Savioli L: Control of neglected tropical diseases. N Engl J Med 2007, 357:1018-1027.

7. Hotez PJ, Brindley PJ, Bethony JM, King CH, Pearce EJ, Jacobson J: Helminth infections: the great neglected tropical diseases. J Clin Invest 2008, 118:1311-1321.

8. Ross AG, Bartley PB, Sleigh AC, Olds GR, Li Y, Williams GM, McManus DP: Schistosomiasis. N Engl J Med 2002, 346:1212-1220.
9. McManus DP, Loukas A: Current status of vaccines for schistosomiasis. Clin Microbiol Rev 2008, 21:225-242.

10. WHO/SCHISTO: The role of chemotherapy in schistosomiasis control. Geneva WHO; 1983, 70.

11. Doenhoff MJ, Cioli D, Utzinger J: Praziquantel: mechanisms of action, resistance and new derivatives for schistosomiasis. Curr Opin Infect Dis 2008, 21:659-667.

12. Botros S, Sayed H, Amer N, El-Ghannam M, Bennett JL, Day TA: Current status of sensitivity to praziquantel in a focus of potential drug resistance in Egypt. Int J Parasitol 2005, 35:787-791.

13. King $\mathrm{CH}$, Muchiri EM, Ouma JH: Evidence against rapid emergence of praziquantel resistance in S. haematobium, Kenya. Emerg Infect Dis 2000, 6:585-594.

14. Silva IM, Thiengo R, Conceição MJ, Rey L, Lenzi HL, Pereira Filho E, Ribeiro PC: Therapeutic failure of praziquantel in the treatment of Schistosoma haematobium infection in Brazilians returning from Africa. Mem Inst Oswaldo Cruz 2005, 100:445-449.

15. Alonso D, Muñoz J, Gascón J, Valls ME, Corachan M: Failure of standard treatment with praziquantel in two returned travellers with Schistosoma haematobium infection. Am J Trop Med Hyg 2006, 74:342-344.

16. Wang ZH: Research progress of schistosomiasis japonica chemotherapy. Hubei I Prev Med 2000, 11:1-3, (in Chinese).

17. Xiao SH, Catto BA: In vitro and in vivo studies of the effect of artemether on Schistosoma mansoni. Antimicrob Agents Chemother 1989, 33:1557-1562.

18. Xiao $S H$, You JQ, Yang YQ, Wang CZ: Experimental studies on early treatment of schistosomal infection with artemether. Southeast Asian J Trop Med Public Health 1995, 26:306-318.

19. Xiao SH, Utzinger J, Chollet J, Endriss Y, N'Goran EK, Tanner M: Effect of artemether against Schistosoma haematobium in experimentally infected hamsters. Int I Parasitol 2000, 30:1001-1006.

20. Utzinger J, Keiser J, Xiao SH, Tanner M, Singer BH: Combination chemotherapy of schistosomiasis in laboratory studies and clinical trials. Antimicrob Agents Chemother 2003, 47:1487-1495.

21. Xiao SH, Tanner M, N'Goran EK, Utzinger J, Chollet J, Bergquist R, Chen MG, Zheng J: Recent investigations of artemether, a novel agent for the prevention of schistosomiasis japonica, mansoni and haematobia. Acta Trop 2002, 82:175-181.

22. Higgins JPT, Green S, (editors): Cochrane Handbook for Systematic Reviews of Interventions Version 4.2.6 [updated September 2006]. The Cochrane Collaboration 2006 [http://www.cochrane.org/resources/ handbook].

23. Jadad AR, Moore RA, Carroll D, Jenkinson C, Reynolds DJ, Gavaghan DJ, McQuay HJ: Assessing the quality of reports of randomized clinical trials: is blinding necessary? Control Clin Trials 1996, 17:1-12.

24. Inyang-Etoh PC, Ejezie GC, Useh MF, Inyang-Etoh EC: Efficacy of a combination of praziquantel and artesunate in the treatment of urinary schistosomiasis in Nigeria. Trans R Soc Trop Med Hyg 2009, 103:38-44.

25. Touré S, Zhang Y, Bosqué-Oliva E, Ky C, Ouedraogo A, Koukounari A, Gabrielli AF, Bertrand S, Webster JP, Fenwick A: Two-year impact of single praziquantel treatment on infection in the national control programme on schistosomiasis in Burkina Faso. Bull World Health Organ 2008, 86:780-787.

26. Tohon ZB, Mainassara HB, Garba A, Mahamane AE, Bosqué-Oliva E, Ibrahim ML, Duchemin JB, Chanteau S, Boisier P: Controlling schistosomiasis: significant decrease of anaemia prevalence one year after a single dose of praziquantel in Nigerien schoolchildren. PLOS Negl Trop Dis 2008, 2:e241-248.

27. Saathoff E, Olsen A, Magnussen P, Kvalsvig JD, Becker W, Appleton CC: Patterns of Schistosoma haematobium infection, impact of praziquantel treatment and re-infection after treatment in a cohort of schoolchildren from rural KwaZulu-Natal/South Africa. BMC Infect Dis 2004, 4:40-49.

28. N'Goran EK, Gnaka HN, Tanner M, Utzinger J: Efficacy and side-effects of two praziquantel treatments against Schistosoma haematobium infection, among school children from Côte d'Ivoire. Ann Trop Med Parasitol 2003, 97:37-51.

29. Borrmann S, Szlezák N, Faucher JF, Matsiegui PB, Neubauer R, Binder RK, Lell B, Kremsner PG: Artesunate and praziquantel for the treatment of Schistosoma haematobium infections: a double-blind, randomized, placebo-controlled study. J Infect Dis 2001, 184:1363-1366. 
30. Campagne G, Garba A, Barkiré H, Vera C, Sidiki A, Chippaux JP: Continued ultrasonic follow-up of children infected with Schistosoma haematobium after treatment with praziquantel. Trop Med Int Health 2001, 6:24-30.

31. Utzinger J, N'Goran EK, N'Dri A, Lengeler C, Tanner M: Efficacy of praziquantel against Schistosoma mansoni with particular consideration for intensity of infection. Trop Med Int Health 2000, 5:771-778.

32. Nash TE, Hofstetter M, Cheever AW, Ottesen EA: Treatment of Schistosoma mekongi with praziquantel: a double-blind study. Am J Trop Med Hyg 1982, 31:977-982.

33. Santos AT, Blas BL, Noseñas JS, Portillo GP, Ortega OM, Hayashi M, Boehme K: Preliminary clinical trials with praziquantel in Schistosoma japonicum infections in the Philippines. Bull World Health Organ 1979, 57:793-799.

34. McMahon JE, Kolstrup N: Praziquantel: a new schistosomicide against Schistosoma haematobium. Br Med J 1979, 2:1396-1399.

35. Katz N, Rocha RS, Chaves A: Preliminary trials with praziquantel in human infections due to Schistosoma mansoni. Bull World Health Organ 1979, 57:781-785.

36. Huang $Y X$, Rong GR, Xu GY, Wang XD, Yang HM, Song HT, Zhang XB, Tu YX: Mass praziquantel chemoprophylaxis against acute schistosomiasis japonica in a flood. Chin J Schisto Control 1998, 10:138-140, (in Chinese).

37. Liu ZG: Effect of intermittent medication with praziquantel for treating schistosomiasis japonica in the endemic seasons. Chin J Parasit Dis Control 1997, 10:21, (in Chinese).

38. Song Y, Bao ZP, Gao ZL, Ning A, Hu QL, Chen MG, Chen FJ, Ge J, Xiao SH, Zhou $\mathrm{XN}, \mathrm{Xu} \mathrm{J}$ : Effect of oral artemether in controlling schistosomiasis in a heavy endemic area of Nanji town, Xinjian county, Jiangxi province. $J$ Trop Med 2006, 6:1182-1185, (in Chinese).

39. Li YS, Chen HG, He HB, Hou XY, Ellis M, McManus DP: A double-blind field trial on the effects of artemether on Schistosoma japonicum infection in a highly endemic focus in southern China. Acta Trop 2005, 96:184-190.

40. N'Goran EK, Utzinger J, Gnaka HN, Yapi A, N'Guessan NA, Kigbafori SD, Lengeler C, Chollet J, Xiao SH, Tanner M: Randomized, double-blind, placebo-control trial of oral artemether for the prevention of patent Schistosoma haematobium infections. Am J Trop Med Hyg 2003, 68:24-32.

41. Utzinger J, N'Goran EK, N'Dri A, Tanner M: Oral artemether for prevention of Schistosoma mansoni infection: randomized controlled trial. Lancet 2000, 355:1320-1325

42. Tian ZY, Xiao SH, Xiao JW, Liu DS, Zhou YC, Zheng J, Chen MG, Qu GS, Zhang XY, Yao XM, Zhang XZ, Zhang DL, Huang GX: Reduction of Schistosoma japonicum infection in an endemic area in Islet with embankment after prophylaxis with oral artemether throughout the transmission season. Chin J Parasito Parasitic Dis 1997, 15:208-211, (in Chinese).

43. Tian ZY, Liu DS, Xiao JW, Yao XM, Zhou YC, Qu GS, Zhang XR: Efficacy investigation of fishermen taking oral artemether on schistosomiasis prevention in Muping Lake. Chin J Schisto Control 1999, 11:317, (in Chinese).

44. Huang AS, Zhou B, Chen WY, Sheng QH, Jing GY, Xiao CY, Xiao SH, Chen MG, Zheng J, Liu HX: Preliminary investigation of effect of artemether in people working with water on schistosomiasis prevention. Chin J Schisto Control 1999, 11:161, (in Chinese).

45. Song Y, Xiao S, Wu W, Zhang S, Xie H, Xu X, Hu X, Cui Q, Chen M, Zheng J: Preventive effect of artemether on schistosome infection. Chin Med J (Engl) 1998, 111:123-127.

46. Xu MS, Xiao SH, Song Q, Tao CG, Xia CG, Wang H, Chen MG, Zheng J, Piao CH, Hu FY, Ou N, Zhang XS: Observation on the effect of artemether on controlling schistosomiasis japonica in an endemic area of marshland. Chin J Parasito Parasitic Dis 1997, 15:212-215, (in Chinese).

47. Wang $J$, Xiao SH, Yang Z, Huang MH, Yang H, Liu YH, Zhou GS, Zheng J, Chen MG: Effect of oral artemether in controlling schistosomiasis in Yunnan mountainous endemic Area. Chin J Parasitol Parasitic Dis 1997, 15:138-142, (in Chinese).

48. Xiao SH, Shi ZG, Zhuo SJ, Wang CZ, Zhang ZG, Chu B, Zheng J, Chen MG: Field studies on preventive effect of artemether against infection with Schistosoma japonicum. Chin J Parasitol Parasitic Dis 1995, 13:170-173, (in Chinese).

49. Xiao SH, Wang JL, Wang CZ, Yang Z, Chu B, Yang H, Liu YH, Zheng J, Chen MG: Protection of the residents from schistosome infection by oral artemether in mountainous endemic area. Chin J Parasitol Parasitic Dis 1996, 14:11-14, (in Chinese).

50. Xu MS, Zhu CG, Wang H, Gao FH, Wu YX, Cui DY, Zhang XZ, Ou N, Wu ZX: Field study on preventive effect of artesunate against infection due to Schistosoma japonicum in an endemic area of marshlands. J Trop Dis Parasitol 1996, 25:198-201, (in Chinese).

51. Xu MS, Zhang SQ, Wang TP, Fang GR, Wang QZ, He JC, Zhang GH, Chen JR, Li JT, Lu YS, Li XS, Xu CS, Bao JR, Yu MX, Huang FY, Ou N, Zhang XS, Piao CH, Hu FY, Cui DY: Field appliance of oral artesunate for prevention of schistosomiasis japonica. J Trop Dis Parasitol 1998, 7:68-71, (in Chinese)

52. Xu MS: The effect analysis of using artesunate to prevent schistosome infection in the field. Chin J Parasit Dis Control 2001, 14:26-27, (in Chinese).

53. Cui JF, Lu GY, Lin GJ, Sun MX, Jiang J, Wu QZ, Li JS: Study of artesunate in preventing schistosome infection in river beach area. Anhui Prev Med 2001, 7:129-130, (in Chinese).

54. Sun MX, Jiang J, Lu GY, Lin GJ, Cui JF, Wu QZ, Li JS: Field investigation of oral artesunate for preventing high risk population from schistosome infection. Anhui J Prev Med 2000, 6:442, (in Chinese).

55. Zhang SJ, Lin DD, Liu YM, Liu HY, Liu ZD, Hu LS, Gao ZL, Hu F, Xu MS, Yi ZH, Wu LJ, Li SW: Clinical trials on preventive effect of artesunate on schistosomiasis japonica. Mod Diagn Treat 2000, 11:68-72, (in Chinese).

56. Yi ZH, Lu M, Feng DC, Wang ZH, Xiang CP, Gou ZQ, Li SW, Wu LJ: Clinical observation of oral artesunate for preventing short-term exposure to infested water population from schistosomiasis. Chin J Schisto Control 2000, 12:100-101, (in Chinese).

57. Liu HY, Liu ZD, Hu LS, Liu YM, Zhang SJ, Hu F, Cheng XY, Li SW, Wu LJ, Xu FS, Xuan YX, Guo Y: Observation on the prevention of schistosomiasis japonica by administration of artesunate long term. Chin J Parasitic Dis Control 1999, 12:214-215, (in Chinese)

58. Liu ZD, Hu LS, Liu YM, Hu GH, Hu F, Qiu YX, Gao ZL, Liu HY, Li JY, Su LH: Expanded experimental study on the prevention of schistosomiasis japonica by oral artesunate. Chin J Parasitic Dis Control 1996, 9:37-39, (in Chinese).

59. Wu LJ, Li SW, Xuan YX, Xu PS, Liu ZD, Hu LS, Zhou SY, Qiu YX, Liu YM: Field application of artesunate in prophylaxis of schistosomiasis: an observation of 346 cases. Chin J Schisto Control 1995, 7:323-327, (in Chinese).

60. Hou XY, McManus DP, Gray DJ, Balen J, Luo XS, He YK, Ellis M, Williams GM, Li YS: A randomized, double-blind, placebo-controlled trial of safety and efficacy of combined praziquantel and artemether treatment for acute schistosomiasis japonica in China. Bull World Health Organ 2008, 86:788-795.

61. Xia CS, Zhao XY, Liu YF, Jiang ZH, Li NP: Observation of the efficacy on schistosomiasis prevention with artesunate and praziquantel. J Prev Med Chin PLA 2000, 18:120-121, (in Chinese).

62. Liu ZG, Yuan XB: Efficacy investigation of praziquantel in schistosomiasis prevention. Hubei J Prev Med 1997, 8:30-31, (in Chinese).

63. Song Y, Xiao SH, Wu W, Zhang SJ, Xie HQ, Xu XP, Hu XY, Cui Q, Chen MG, Zheng J: The preventive effect of artemether in protection of people from schistosome infection during fighting against flood. Chin J Parasitol Parasitic Dis 1997, 15:133-137, (in Chinese).

64. Chen HG, Lin DD, Li YS, Liu YM, McManus DP, Huang XH, Feng Z: Studies on effect of artemether to control infection and prevent acute infection of Schistosoma japonicum in high endemic areas. Chin J Schisto Control 2006, 18:32-35, (in Chinese).

65. Xu MS, Zhu CG, Wang H, Gao FH, Wu YX, Cui DY, Zhang XZ, Ou N, Wu ZX: Study on preventive effect of artesunate against infection due to Schistosoma japonicum in an endemic area of marshlands. Chin J Schisto Control 1997, 9:268-271, (in Chinese).

66. Hou XY, Li YS, Luo XS, He YK, Yu XL, Fu X, Zhou J, Shi MZ, Liu ZC, Wang YY, Li Y, Wei WY: Clinical research of combination praziquantel and artemether in treating acute schistosomiasis japonica. Chin J Schisto Control 2006, 18:99-102, (in Chinese).

67. Huang YX, Wang WF, Xue ZQ, Yang SJ, Chen YQ, Wu YX, Zhou JX: Double blind investigation of praziquantel in treating schistosomiasis japonica. Jiangsu Med Drug 1983, 1:19-21, (in Chinese).

68. Olliaro PL, Vaillant MT, Belizario VJ, Lwambo NJ, Ouldabdallahi M, Pieri OS, Amarillo ML, Kaatano GM, Diaw M, Domingues AC, Favre TC, Lapujade O, Alves F, Chitsulo L: A multi-centre randomized controlled trial of the efficacy and safety of single-dose praziquantel at $40 \mathrm{mg} / \mathrm{kg}$ vs. $60 \mathrm{mg} /$ 
$\mathrm{kg}$ for treating intestinal schistosomiasis in the Philippines, Mauritania, Tanzania and Brazil. PLoS Negl Trop Dis 2011, 5:e1165.

69. Hua HY, Liang YS, Zhang Y, Wei JF, Guo HX: The sensitivity of artesunate against Schistosoma japonicum decreased after 10 years of use in China. Parasitol Res 2010, 107:873-878.

70. Zhou ZB, Li WT, Xiong SL, Xu YB, Li YB, Lan YH, Zhao CG, Rao CD, Mao AJ, Liu SQ, Du GY, Li Y: Clinical analysis of praziquantel in treating schistosomiasis japonica: 1107 cases report. Yunnan Med Drug 1983, 4:148-152, (in Chinese)

71. Utzinger J, Zhou XN, Chen MG, Bergquist R: Conquering schistosomiasis in China: the long march. Acta Trop 2005, 96:69-96.

72. Wang ZH: Chemical treatment of schistosomiasis japonica in China. J Clin Intern Med 2006, 23:302-304, (in Chinese).

73. Xiao SH: Study on prevention and cure of artemether against schistosomiasis. Chin J Schisto Control 2005, 17:310-320, (in Chinese).

74. Xiao SH: Development of antischistosomal drugs in China, with particular consideration to praziquantel and the artemisinins. Acta Trop 2005, 96:153-167.

75. Midzi N, Sangweme D, Zinyowera S, Mapingure MP, Brouwer KC, Kumar N, Mutapi F, Woelk G, Mduluza T: Efficacy and side effects of praziquantel treatment against Schistosoma haematobium infection among primary school children in Zimbabwe. Trans R Soc Trop Med Hyg 2008, 102:759-766.

76. Ma YJ, Guo M, Liu JF: Chemotherapeutic drugs against schistosomiasis japonica. Endemic Dis Bull 2007, 22:68-69, (in Chinese).

77. Xiao SH, Yue WJ, Yang YQ, You JQ: Susceptibility of Schistosoma japonicum to different developmental stages to praziquantel. Chin Med J (Engl) 1987, 100:759-768.

78. Keiser J, Chollet J, Xiao SH, Mei JY, Jiao PY, Utzinger J, Tanner M: Mefloquine-an aminoalcohol with promising antischistosomal properties in mice. PLoS Negl Trop Dis 2009, 3:e350.

79. Wu WL, Huang YY, Zhou XZ, Wang JX, Zhang SY, Zhang YM, Lu JY, He WB, Lang YG, Tang HJ, Yang SG: A 19-year follow-up study on praziquantel treatment for schistosomiasis. Chin J Schisto Control 1998, 10:215-217, (in (hinese).

80. Adam I, Elwasila E, Homeida M: Praziquantel for the treatment of schistosomiasis mansoni during pregnancy. Ann Trop Med Parasitol 2005, 99:37-40.

81. Fallon $P G$, Tao LF, Ismail MM, Bennett JL: Schistosome resistance to praziquantel: Fact or artifact? Parasitol Today 1996, 12:316-320

82. Fallon PG: Schistosome resistance to praziquantel. Drug Resist Updat 1998, 1:236-241.

83. Seto EY, Wong BK, Lu D, Zhong B: Human schistosomiasis resistance to praziquantel in china: should we be worried? Am J Trop Med Hyg 2011, 85:74-82.

84. Shi MZ, Yu DB, Wei WY, Zhang CS, He HB, Yang GF, Li GP, Ren MY: Experimental study on susceptibility of praziquantel against Schistosoma japonicum in repeated chemotherapy areas in Dongting Lake region. Chin J Schisto Contr 2004, 16:171-173, (in Chinese).

85. Doenhoff MJ, Pica-Mattoccia L: Praziquantel for the treatment of schistosomiasis: its use for control in areas with endemic disease and prospects for drug resistance. Expert Rev Anti Infect Ther 2006, 4:199-210.

86. Danso-Appiah A, de Vlas SJ: Interpreting low praziquantel cure rates of Schistosoma mansoni infections in Senegal. Trends Parasitol 2002, 18:125-129.

87. Ismail M, Metwally A, Farghaly A, Bruce J, Tao LF, Bennett JL: Characterization of isolates of Schistosoma mansoni from Egyptian villagers that tolerate high doses of praziquantel. Am J Trop Med Hyg 1996, 2:214-218

88. Liang YS, Coles GC, Doenhoff MJ, Southgate VR: In vitro responses of praziquantel-resistant and -susceptible Schistosoma mansoni to praziquantel. Int J Parasitol 2001, 11:1227-1235.

89. Kenworthy JD, Ye P, Wu GC, Yu H, Shi YJ, Li H, Coles GC: Field evaluation of a test for praziquantel resistance in Schistosoma sp. Vet Parasitol 2003, 1:83-87.

90. Ismail M, Botros S, Metwally A, William S, Farghally A, Tao LF, Day TA, Bennett JL: Resistance to praziquantel: direct evidence from Schistosoma mansoni isolated from Egyptian villagers. Am J Trop Med Hyg 1999, 60:932-395.

91. Gryseels B, Mbaye A, de Vlas SJ, Stelma FF, Guissé F, Van Lieshout L, Faye D, Diop M, Ly A, Tchuem-Tchuenté LA, Engels D, Polman K: Are poor responses to praziquantel for the treatment of Schistosoma mansoni infections in Senegal due to resistance? An overview of the evidence. Trop Med Int Health 2001, 6:864-873.

92. King $\mathrm{CH}$, Muchiri EM, Ouma JH: Evidence against rapid emergence of praziquantel resistance in Schistosoma haematobium, Kenya. Emerg Infect Dis 2000, 6:585-594.

93. Kasinathan RS, Morgan WM, Greenberg RM: Schistosoma mansoni express higher levels of multidrug resistance-associated protein 1 (SmMRP1) in juvenile worms and in response to praziquantel. Mol Biochem Parasitol 2010, 173:25-31.

94. Doenhoff MJ, Hagan P, Cioli D, Southgate V, Pica-Mattoccia L, Botros S, Coles G, Tchuem Tchuenté LA, Mbaye A, Engels D: Praziquantel: its use in control of schistosomiasis in sub-Saharan Africa and current research needs. Parasitology 2009, 136:1825-1835.

95. Le WJ, You JQ, Yang YQ, Mei JY, Guo HF, Yang HZ, Zhang CW: Studies on the efficacy of artemether in experimental schistosomiasis. Acta Pharm $\operatorname{Sin}$ 1982, 17:187-193.

96. Le WJ, You JQ, Mei JY: Chemotherapeutic effect of artesunate in experimental schistosomiasis. Acta Pharm Sin 1983, 18:619-621.

97. Chen DJ, Fu LF, Shao PP, Wu FZ, Shu H, Ren CS, Sheng XL: Experimental studies on antischistosomal activity of qinghaosu. Zhong Hua Yi Xue Zha Zhi 1980, 60:422-425.

98. Bartley PB, Glanfield A, Li YS, Stanisic DI, Duke M, Jones MK, McManus DP: Artemether treatment of prepatent Schistosoma japonicum induces resistance to reinfection in association with reduced pathology. Am J Trop Med Hyg 2008, 78:929-935.

99. Utzinger J, Xiao SH, N'Goran EK, Bergquist R, Tanner M: The potential of artemether for the control of schistosomiasis. Int J Parasitol 2001, 31:1549-1562.

100. Zhou J, Wu GH: Development of the drug to prevent schistosomiasis japonica. Chin J Dis Control Prev 2002, 6:71-73, (in Chinese).

101. Xiao SH: Study on prevention and cure of artemether against schistosomiasis. Chin J Schisto Control 2005, 17:310-320, (in Chinese).

102. Division of Science and Education of Chinese Ministry of Health: Research on artemether and artesunate for prevention of schistosomiasis. China Medical News 1999, 13:6-8, (in Chinese).

103. Xu MS: Research progress of artemisinin, artemether and artesunate used for schistosomiasis prevention. Chin J Schisto Control 1998 4:251-253, (in Chinese).

104. Hua HY, Liang YS, Zhang Y, Wei JF, Guo HX: The sensitivity of artesunate against Schistosoma japonicum decreased after 10 years of use in China. Parasitol Res 2010, 107:873-878.

105. Liu R, Dong HF, Jiang MS: The sensitivity of artesunate against Schistosoma japonicum decreased after 10 years of use in China? Parasitol Res 2011.

106. Dondorp AM, Nosten F, Yi P, Das D, Phyo AP, Tarning J, Lwin KM, Ariey F, Hanpithakpong W, Lee SJ, Ringwald P, Silamut K, Imwong M, Chotivanich K, Lim P, Herdman T, An SS, Yeung S, Singhasivanon P, Day NP, Lindegardh N, Socheat $\mathrm{D}$, White $\mathrm{NJ}$ : Artemisinin resistance in Plasmodium falciparum malaria. N Engl I Med 2009, 361:455-467.

107. Editorial: Has artemisinin resistance spread already? Lancet 2011, 377:272.

108. Cui W: WHO urges the phasing out of artemisinin based monotherapy for malaria to reduce resistance. BMJ 2011, 342:d2793.

109. Bergquist $R$, Johansen MV, Utzinger J: Diagnostic dilemmas in helminthology: what tools to use and when? Trends Parasitol 2009, 25:151-156.

110. Danso-Appiah A, Garner P, Olliaro PL, Utzinger J: Treatment of urinary schistosomiasis: methodological issues and research needs identified through a Cochrane systematic review. Parasitology 2009, 136:1837-1849.

111. Liu SJ, Cao HN, Tao B, Li QR, Cheng LG, Wu ZX, Xiong TS, Deng LX, Chen LH, Zuo XX, Song GX, Zhang R: Efficacy investigation of praziquantel in treating different infection level schistosomiasis. Chin J Parasitol Parasitic Dis 1989, 7:64-65, (in Chinese).

112. Li YP, (editor): Evidence-based medicine. Beijing: Higher Education Press; 2003, (in Chinese).

113. Danso-Appiah A, Utzinger J, Liu J, Olliaro P: Drugs for treating urinary schistosomiasis. Cochrane Database Syst Rev 2008, 3:CD000053.

114. Saconato $\mathrm{H}$, Atallah A: Interventions for treating schistosomiasis mansoni. Cochrane Database Syst Rev 2000, , 2: CD000528.

115. Wang LD, Utzinger J, Zhou XN: Schistosomiasis control: experiences and lessons from China. Lancet 2008, 372:1793-1795. 
116. Wang LD, Guo JG, Wu XH, Chen HG, Wang TP, Zhu SP, Zhang ZH, Steinmann P, Yang GJ, Wang SP, Wu ZD, Wang LY, Hao Y, Bergquist R, Utzinger J, Zhou XN: China's new strategy to block Schistosoma japonicum transmission: experiences and impact beyond schistosomiasis. Trop Med Int Health 2009, 14:1475-1483.

117. Jiang MS, Liu R, Zhao QP, Dong HF, Guo Y: Social epidemiological thinking about schistosomiasis. Chin J Schisto Contr 2010, 22:201-205, (in (hinese).

118. Gray DJ, McManus DP, Li YS, Williams GM, Bergquist R, Ross AG: Schistosomiasis elimination: lessons from the past guide the future. Lancet Infect Dis 2010, 10:733-736.

doi:10.1186/1756-3305-4-201

Cite this article as: Liu et al:: Efficacy of praziquantel and artemisinin derivatives for the treatment and prevention of human schistosomiasis: a systematic review and meta-analysis. Parasites \& Vectors 2011 4:201.

\section{Submit your next manuscript to BioMed Central} and take full advantage of:

- Convenient online submission

- Thorough peer review

- No space constraints or color figure charges

- Immediate publication on acceptance

- Inclusion in PubMed, CAS, Scopus and Google Scholar

- Research which is freely available for redistribution

Submit your manuscript at www.biomedcentral.com/submit 